\title{
Dirección de tesis doctorales como reflejo de la Biblioteconomía y Documentación académica española: actores y temas
}

\author{
Supervision of doctoral dissertations as a \\ reflection of Library and Information Science \\ in Spain: actors and topics
}

\author{
Gregorio González-Alcaide; Aurora González-Teruel
}

Cómo citar este artículo:

González-Alcaide, Gregorio; González-Teruel, Aurora (2020). “Dirección de tesis doctorales como reflejo de la Biblioteconomía y Documentación académica española: actores y temas”. Profesional de la información, v. 29, n. 4, e290441.

https://doi.org/10.3145/epi.2020.jul.41

Artículo recibido el 10-01-2020

Aceptación definitiva: 09-06-2020

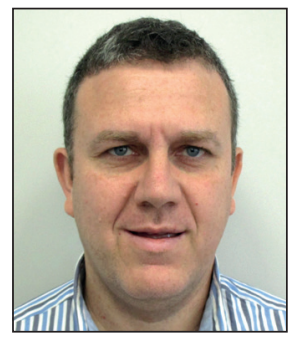

Gregorio González-Alcaide $₫$
https://orcid.org/0000-0003-3853-5222
Universitat de València
Departamento de Historia de la Ciencia y
Documentación
Avda. Blasco Ibáñez, 15
46010 Valencia, España
gregorio.gonzalez@uv.es

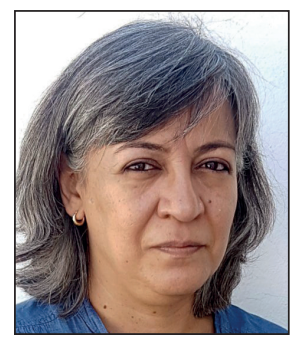

Aurora González-Teruel
https://orcid.org/0000-0001-9304-2928
Universitat de València
Departamento de Historia de la Ciencia y
Documentación
Avda. Blasco Ibáñez, 15
46010 Valencia, España
aurora.gonzalez@uv.es

\section{Resumen}

Las tesis doctorales posibilitan la transmisión de la capacidad investigadora a las futuras generaciones y la consolidación de las líneas de investigación de un área de conocimiento. Se caracteriza la Biblioteconomía y Documentación de las universidades públicas españolas a partir de la dirección de tesis doctorales por los académicos del área. Se han identificado los docentes activos en el curso 2019-2020, su fecha de nombramiento como funcionarios, las tesis que han dirigido y su participación en publicaciones en revistas científicas. Se han analizado 644 tesis. Un $23 \%$ de los titulares de universidad nunca ha participado en la dirección de tesis y la mayoría de los titulares y catedráticos de universidad (60\%) tienen un promedio de direcciones/año desde su nombramiento por debajo de la media del área. Existe una elevada concentración en unas pocas instituciones y directores (el $8 \%$ del profesorado ha dirigido el $42 \%$ de las tesis), con importantes desequilibrios en la participación de las mujeres (promedio de 1,8 tesis dirigidas frente a 2,6 en el caso de los hombres). Unidades y servicios de información, estudios métricos de la publicación científica y fuentes de información son los temas del $47 \%$ de las tesis. Muchos de los docentes con 10 o más direcciones $(n=18)$ adolecen de una especialización temática, no existiendo una relación entre su relevante papel en las tareas de dirección y su participación en las actividades de investigación a través de publicaciones en revistas científicas. Los resultados alertan acerca de que la consideración de la dirección de tesis como un importante mérito curricular puede contribuir a reforzar el fenómeno de la concentración del poder y capital social en un reducido grupo de directores, provocando una reducción de la pluralidad de enfoques y direcciones menos eficientes. Los desequilibrios descritos se erigen como una amenaza más que se suma a la crisis epistemológica y de los estudios universitarios de esta área de conocimiento.

\section{Palabras clave}

Tesis doctorales; Producción científica; Información y Documentación; Biblioteconomía y Documentación; Concentración de poder; Capital social; Desigualdad de género; Brecha de género; Especialización temática; Investigación; Temas de investigación; Mérito académico; Profesores universitarios; España.

\section{Abstract}

Doctoral dissertations enable the transfer of research skills and capacities to future generations and the consolidation of lines of research in a given area of knowledge. The field of Library and Information Science in public universities in Spain 
is characterized by the supervision of doctoral theses by academics in the area. We identified active professors during the 2019-2020 academic year, their date of appointment as civil servants within the public university system, the dissertations that they supervised, and their participation in papers published in scientific journals. The analysis included 644 theses. About a quarter (23\%) of university faculty have never supervised a doctoral thesis, and most faculty members and tenured professors (60\%) show a lower than average rate of adviserships per year since their academic appointment. There is a high concentration of PhD advisers in just a few institutions and academics ( $8 \%$ of university professors have supervised $42 \%$ of the dissertations), with an important gender imbalance: women supervised an average of 1.8 dissertations, compared with 2.6 for men. Information units and services, study metrics and scientific publications, and information sources are the topics of $47 \%$ of the dissertations. Many of the professors with 10 or more adviserships $(n / N$ $=12 / 18$ ) lack a subject area specialization, and their role in PhD supervision was not related to their participation in research activities oriented toward publishing in scientific journals. Our results suggest that considering supervision of doctoral theses as an important academic merit could contribute to a further concentration of power and social capital among a small group of advisers. This phenomenon could reduce the plurality of topics addressed and favor suboptimal adviserships. The imbalances described emerge as another threat, exacerbating the epistemological crisis in the discipline and in the university studies in this area of knowledge.

\section{Keywords}

Doctoral dissertations; Scientific production; Library and Information Science; Concentration of power; Social capital; Gender inequality; Gender gap; Subject specialization; Research; Research topics; Academic merit; University professors; Spain.

\section{Introducción}

En el año 2002, Delgado-López-Cózar proponía en su libro La investigación en biblioteconomía y documentación una teoría para explicar el nacimiento y desarrollo de la Biblioteconomía y Documentación (ByD). Ésta se basaba en una sucesión de etapas que constituyen el ciclo vital de la disciplina: necesidad, práctica, profesión, enseñanza/educación y ciencia. La existencia de una necesidad crea una práctica y su ejercicio una profesión, que para su adecuado desempeño requiere de formación. Esta formación está constituida por principios prácticos sobre los que se reflexiona, se investiga y se teoriza. Con ello, nace el conocimiento científico que, sistematizado, da lugar a la ciencia. Pero la investigación científica se sustenta en una organización social. Tal y como refiere Delgado-López-Cózar (2002) siguiendo a Whitley (1984), existe una relación de dependencia entre los productos de la investigación y los medios en los que dichos productos son generados. Así la institucionalización social y cognitiva de un área de investigación son la medida de su grado de desarrollo. La institucionalización social se materializa en las universidades a través de la creación de departamentos universitarios que imparten estudios de grado y posgrado, con una comunidad de profesores dedicado a las tareas docentes e investigadoras. Por otra parte, la institucionalización cognitiva está estrechamente relacionada con la social, ya que supone la existencia de un consenso alcanzado por la comunidad académica y científica en lo referente a las nociones teóricas que sustentan la disciplina, los problemas centrales que deben ser abordados y los enfoques metodológicos más apropiados para ello (Whitley, 1984).

\section{La institucionalización social y cognitiva de un área de investigación son la medi- da de su grado de desarrollo}

Las tesis doctorales constituyen probablemente el tipo documental que permite caracterizar con mayor precisión la institucionalización de una disciplina científica, tanto social como cognitiva, ya que están conectadas con las líneas de investigación de las universidades, los programas de doctorado y los directores responsables de su tutela (Finlay et al., 2012; Sugimoto, 2016). Sin embargo, la mayor parte de los estudios que han tratado de caracterizar el desarrollo o institucionalización de la investigación española en ByD se han centrado en el análisis de los artículos de revista (e.g. De-Moya-Anegón; Jiménez-Contreras; De-la-Moneda-Corrochano, 1998; Ferran-Ferrer et al., 2017; González-Alcaide; Gorraiz, 2018; Guallar et al., 2017; Kawalec, 2013) y de forma más puntual en los libros y las comunicaciones a congresos (Fuentes-Pujol; González-Quesada, 2001).

Jiménez-Contreras, Ruiz-Pérez y Delgado-López-Cózar (2014) consideran que las tesis doctorales pueden constituir una destacada fuente de información en relación con cuatro dimensiones:

- tendencias de investigación,

- capacidad formativa de los investigadores,

- calidad o excelencia de las investigaciones efectuadas, y

- estructuras organizativas de poder académico.

Existe una amplia bibliografía que ha analizado las tesis doctorales en diferentes áreas, disciplinas y especialidades, si bien, en su mayor parte se limitan a estudios descriptivos que analizan la productividad de las tesis, describiendo la evolución diacrónica o la distribución de las mismas por universidades o temas. Solamente un número puntual de estudios, como el de Repiso, Torres-Salinas y Delgado-López-Cózar (2011) referido al área de televisión o el de Maz-Machado et al. (2012) en el área de la educación matemática han considerado como parte del análisis las características de las comu- 
nidades académicas responsables de la dirección de las mismas. En relación con los estudios que han analizado las tesis doctorales de ByD en España, la diversidad de los enfoques, especialmente en los criterios de identificación y búsqueda de las tesis, hace que los resultados sean ciertamente dispares. Así, para el conjunto de la disciplina, Abadal (1994) identificó 30 tesis doctorales del área en el periodo 1976-1993 y Delgado-López-Cózar (2002) 205 en el periodo 1976-1996, afirmando que la evolución de las tesis en ese periodo son la crónica del proceso de institucionalización social de la ByD española. En lo que sí parecen estar de acuerdo ambos autores es en el peso de las tesis de corte bibliométrico. Otros trabajos que han analizado las tesis del área de ByD son los de Fuentes-Pujol y González-Quesada (2002) que cubren el período 1976-2001, resaltando la eclosión de tesis experimentada en la década de 1990 y el tema bibliométrico como el más destacado; y el de Zapico-Alonso et al. (2002) que cubre el período 1976-1998 destacando de forma similar la eclosión de tesis específicas vinculadas a departamentos de documentación a partir de la década de 1990. Uno de los últimos trabajos en abordar el estudio de las tesis del área ha sido el de Oliva-Marañón (2014) que, cubriendo el periodo 2001-2012, obtuvo 319 tesis que responden en su mayoría a la línea de investigación de políticas de información, seguida por la bibliometría. Otros estudios se han centrado en universidades o departamentos específicos (López-Yepes, 2002a; 2002b; Agustín-Lacruz; Salvador-Oliván; Velasco-de-la-Peña, 2009; Ortiz-Sánchez; Martín-Moreno, 2011). Finalmente, algunos estudios han analizado las tesis presentadas en relación con determinados temas, como la biblioteconomía y las bibliotecas (Orera-Orera, 2004), la documentación informativa (López-Yepes; Fernández-Bajón; Prat-Sedeño, 2005a) o las tesis bibliométricas (López-López, 1996; Delgado-López-Cózar et al., 2006).

Más allá de los trabajos meramente descriptivos que han analizado las distribuciones cuantitativas de las características bibliográficas de las tesis doctorales como tipo documental, cabe resaltar las contribuciones de López Yepes, que propuso la aplicación en el área de la ByD de conceptos de gran relevancia e interés para caracterizar los temas y los vínculos que se pueden analizar a partir de los procesos de dirección de las tesis doctorales. Así, mediante el concepto de foco de investigación, analizó el impulso de determinados temas a partir de la dirección de tesis doctorales por parte de un docente vinculado a un departamento o universidad. López-Yepes aplicó el concepto de escuela académica, vinculado con la noción de colegio invisible de Crane (1972) referida al estudio de las estructuras sociales más allá de las relaciones formales, para analizar los vínculos comunes creados entre un conjunto de docentes e investigadores. Los temas o líneas de investigación comunes derivadas de los vínculos de director-dirigido o de compartir un director de tesis común, podían tener señas de identidad comunes (como doctrinas o estilos de dirección) y mantenían generalmente contactos informales o personales que podían plasmarse en vínculos cooperativos a nivel investigador o de participación en tribunales de tesis. Estas escuelas podían ser representadas en forma de genealogías de sucesivas generaciones de directores y alumnos dirigidos (López-Yepes, 2002a; 2002b; López-Yepes; Fernández-Bajón; Prat-Sedeño, 2005a; Repiso; Torres-Salinas; Delgado-López-Cózar, 2011). Este mismo autor incidió en la necesidad de establecer mecanismos que permitiesen mejorar la evaluación de la calidad de las tesis, y particularmente medir su relevancia e impacto a través de indicadores más allá de los procesos que regulan su desarrollo y defensa en las universidades donde son presentadas (López-Yepes; Ros-García, 2003; López-Yepes; Fernández-Bajón; Prat-Sedeño, 2005b). De gran relevancia resultan también las contribuciones de Delgado-López-Cózar et al. (2006) y de Olmeda-Gómez et al. (2009), que introdujeron la metodología del Análisis de redes sociales para el estudio de las tesis doctorales de la disciplina, con el propósito de que la identificación de la estructura social subyacente a los procesos de dirección y participación en los tribunales de evaluación de las tesis facilitase la identificación de las escuelas académicas y la interpretación del fenómeno de la concentración de tesis y la acumulación del capital social en unos pocos directores y miembros de tribunales.

En este contexto, y partiendo de que no hay ciencia sin estructura social que la sustente, este trabajo tiene el objetivo de caracterizar la ByD de las universidades públicas españolas desde la perspectiva de la dirección de tesis doctorales, entendida como una de las funciones que ejercen los docentes universitarios orientada a formar y validar la capacidad investigadora de los futuros docentes y profesionales y a generar o continuar las líneas de investigación propias del área de conocimiento. Por lo tanto, se pretende caracterizar un área de conocimiento universitaria a través del ejercicio de una función propia de los actores que la integran, no específicamente las tesis de ByD.

De forma específica, este trabajo trata de dar respuesta a las siguientes preguntas de investigación:

- ¿Cuál es el volumen de tesis dirigidas por la población de docentes actuales del área y cuál ha sido su evolución a lo largo del tiempo? ¿En qué medida las direcciones de tesis reflejan un óptimo aprovechamiento del capital académico disponible?

- ¿Cuál es el grado de concentración del número de tesis dirigidas a nivel de directores e instituciones? ¿Existen sesgos de género, por categoría profesional o de otro tipo en relación con las direcciones?

- ¿Qué incidencia tienen las codirecciones de tesis?

- ¿Cuáles son las principales materias o líneas de investigación de las tesis doctorales? ¿En qué medida se conectan esas líneas con las áreas temáticas de las publicaciones de los directores y directoras de tesis? 


\section{Metodología}

\subsection{Identificación de la población de docentes del área de conocimiento de ByD de las universidades pú- blicas españolas}

Se consultaron los datos agregados más recientes (curso académico 2017-2018) de la Estadística de personal de las universidades (EPU) que proporciona el Sistema integrado de información universitaria (SIIU), lo que posibilitó determinar el personal docente e investigador (PDI) adscrito al área de conocimiento de ByD en las universidades públicas españolas. Con este valor como referencia, se consultaron los directorios de personal de las webs de las universidades públicas donde se imparten estudios específicos de información y documentación o se tenía constancia de la presencia de PDI del área, lo que permitió determinar, además de su nombre y apellidos, su afiliación institucional, estatus académico y sexo.

En relación con el estatus académico de los PDI, se tuvieron en cuenta las figuras "estables" de funcionariado y personal contratado que caracterizan la actual carrera académica docente de las universidades españolas:

- Catedrático de universidad (CU),

- Titular de universidad (TU),

- Contratado doctor (CD), y

- Ayudante doctor (AD).

Además de

- Catedrático de escuela universitaria (CEU), y

- Titular de escuela universitaria (TEU).

Bajo el epígrafe de "otros" se agruparon otras categorías y figuras menos estables o con dedicación a tiempo parcial, como profesores asociados o figuras contractuales específicas propias del desarrollo autonómico y de determinadas universidades, como profesores colaboradores o de sustitución.

\subsection{Identificación y descarga de las tesis doctorales dirigidas por los docentes identificados, normalización de datos y obtención de información adicional}

Para la identificación de las tesis doctorales dirigidas por el PDI identificado, se realizó una búsqueda en la base de datos Teseo a partir de sus nombres y apellidos. Además, se realizaron búsquedas complementarias por departamentos, descriptores y palabras clave para comprobar la adecuada identificación del conjunto de tesis dirigidas por estos docentes. También se comprobó la exhaustividad de la identificación de las tesis recogidas en Teseo consultando otras fuentes bibliográficas, como Dialnet, así como los catálogos y repositorios de las universidades a las que pertenecían los docentes. https://www.educacion.gob.es/teseo https://dialnet.unirioja.es

Una vez identificadas, se descargaron los registros y se generó una base de datos relacional local con Microsoft Access para revisar y homogeneizar los datos y registrar la información adicional necesaria para el análisis. Esta revisión permitió comprobar la adecuada recuperación de información, eliminar registros no pertinentes, por homonimias u otros factores, y completar algunos registros que en Teseo carecían de resumen.

La información adicional que se obtuvo fue la relativa a la fecha de nombramiento de los CU y TU según el Boletín oficial del estado y los datos sobre publicación científica de los docentes con un mayor número de tesis dirigidas (10 o más). En concreto, se buscaron los artículos publicados por dichos docentes en revistas indizadas en las bases de datos Science Citation Index (SCl), Social Sciences Citation Index (SSCl) y Scopus y se construyó una lista con las referencias bibliográficas únicas, eliminando repeticiones. Para su identificación y recuperación se buscó en estas bases de datos por autor, incluyendo todas las variantes conocidas de su firma, y en los perfiles de investigador (Orcid, Google Scholar Citations, ResearchID y Scopus) en caso de disponer de ellos.

La identificación y descarga de los datos se efectuó en octubre de 2019, recogiendo por tanto el presente estudio información correspondiente a la comunidad académica de docentes activos del área de ByD y a las tesis que han dirigido hasta principios del curso académico 2019-2020.

\subsection{Análisis de la información y cálculo de indicadores}

Una vez descritas las distribuciones generales de la población de PDI analizada a partir de las variables que fundamentan los análisis posteriores (estatus académico, sexo y fecha de nombramiento de los CU y TU), se analizaron los aspectos que se describen a continuación:

a) Número de tesis dirigidas: evolución diacrónica, distribución de la dirección de tesis por estatus académico, sexo y umbrales de productividad

Se realizó un análisis descriptivo de las tesis dirigidas a partir de los siguientes indicadores que se presentan de forma desagregada por categoría académica y sexo:

- Evolución diacrónica del número de tesis dirigidas por quinquenio.

- Distribución del número de tesis con un único director y codirigidas. 
- Grado de participación de los docentes en el proceso de dirección (\% de docentes que han dirigido tesis y promedio de tesis dirigidas).

- Distribución del profesorado en función del número o umbral de tesis dirigidas.

- Participación de las mujeres en las tesis codirigidas, determinando la posición u orden que ocupan como codirectoras y las interacciones de sexo en las direcciones.

b) Distribución del número de tesis doctorales dirigidas por universidades y grado de optimización del rendimiento de la dirección de tesis

Para medir la optimización de la capacidad académica disponible para la dirección de tesis doctorales en el caso las figuras de CU y TU (las que concentran el mayor número de direcciones y asumen la responsabilidad principal de la formación de los futuros docentes e investigadores), se ha calculado el indicador de productividad que hemos denominado Índice de rendimiento de la dirección de tesis (RDT), entendido como el promedio entre el número de años completos de trabajo de los CU y TU dividido por el número de tesis dirigidas, expresado de forma global así como por universidades.

\section{c) Temas de la producción de tesis doctorales y grado de especialización de los directores}

Para asignar categorías temáticas a las tesis analizadas, se optó por una clasificación que aportaba tres cualidades: la posibilidad de comparar resultados, la estabilidad y la objetividad. Se tomó como referencia el Tesauro de ByD del CSIC (Mochón-Bezares; Sorli-Rojo, 2002) que, aunque fue editado en el año 2002 y carece de descriptores propios de los aspectos más actuales de la ByD, reunía las cualidades descritas, además de facilitar la interpretación transparente de los resultados consultando los descriptores de cada árbol jerárquico del tesauro.

El proceso se inició con la asignación de descriptores del tesauro (hasta un máximo de tres). Cuando no existía un descriptor adecuado, se generó uno propio vinculándolo con un árbol jerárquico. Estos árboles jerárquicos fueron el punto de partida de las categorías en las que se clasificaron las tesis. En el Anexo se presenta la equivalencia entre los árboles jerárquicos del tesauro y la clasificación empleada en el presente estudio, así como los descriptores que se asignaron no presentes en el tesauro.

También se clasificaron los artículos publicados por los directores de tesis con mayor número de direcciones (10 ó más). Ambos procesos fueron realizados por los dos autores de forma independiente. Las discrepancias se discutieron y se resolvieron de forma consensuada.

Para caracterizar el grado de especialización temática de los directores más prolíficos, se calculó el Índice de especialización temática de directores (ETD tesis), que determina la concentración o dispersión de las categorías temáticas de las tesis dirigidas. Para ello, tras clasificar las tesis y vincularlas con su director, se identificaron el número de tesis de la categoría temática en la que se había dirigido más tesis, dividiéndose ese valor entre el número total de tesis dirigidas. Así, los directores especializados que concentran la mayor parte de su esfuerzo de dirección en una única categoría temática presentarán valores próximos a uno, mientras que ese valor se irá reduciendo progresivamente en la medida que presenten una mayor dispersión entre las diferentes categorías. De forma similar (ETD publicación) se caracterizó la especialización temática de la producción científica de artículos en revistas indizadas en SCl, SCCl y Scopus de estos docentes. Para representar gráficamente las áreas temáticas de las tesis dirigidas y de los artículos publicados por los directores más prolíficos, se utilizó la aplicación RAWgraphs (Mauri et al., 2017).

\section{Resultados}

\subsection{Características de la comunidad académica española del área de conocimiento de ByD}

A comienzos del curso académico 2019-2020, la comunidad académica española de ByD la formaban 321 docentes (51,1\% mujeres y $48,9 \%$ hombres). El profesorado funcionario representaba el $53,5 \%$ del total, con un predominio de los TU (36,4\%), seguidos por los CU (10,9\%). También se han tenido en cuenta los CEU del área (0,6\%) y los TEU (5,6\%). En cuanto a las figuras contractuales, los CD representaban un $8,7 \%$ del profesorado y los AD un 7,2\%, mientras que "otras" figuras contractuales suponían el 30,5\% del profesorado. Junto al elevado peso de esta última categoría, es significativo el reducido número de mujeres $\mathrm{CU}$, pues únicamente constituyen el 37,1\% del profesorado de esta categoría frente al $62,9 \%$ de hombres (tabla 1 ).

Tabla 1. Distribución por categoría académica y sexo del profesorado adscrito al área de conocimiento de ByD en las universidades públicas españolas

\begin{tabular}{|c|c|c|c|c|c|c|}
\hline \multirow{2}{*}{ Categoría } & \multicolumn{2}{|c|}{ Mujeres } & \multicolumn{2}{|c|}{ Hombres } & \multicolumn{2}{|c|}{ Total } \\
\hline & $\mathbf{N}$ & \% categoría & $\mathbf{N}$ & \% categoría & $\mathbf{N}$ & $\%$ del total de PDI \\
\hline $\mathrm{CU}$ & 13 & 37,1 & 22 & 62,9 & 35 & 10,9 \\
\hline TU & 65 & 55,6 & 52 & 44,4 & 117 & 36,4 \\
\hline CEU & 1 & 50,0 & 1 & 50,0 & 2 & 0,6 \\
\hline TEU & 11 & 61,1 & 7 & 38,9 & 18 & 5,6 \\
\hline$C D$ & 19 & 67,9 & 9 & 32,1 & 28 & 8,7 \\
\hline$A D$ & 10 & 43,5 & 13 & 56,5 & 23 & 7,2 \\
\hline Otros & 45 & 45,9 & 53 & 54,1 & 98 & 30,5 \\
\hline Total & 164 & 51,1 & 157 & 48,9 & 321 & 100 \\
\hline
\end{tabular}


La tabla 2 muestra la progresiva incorporación de docentes a las plazas de funcionariado, siendo particularmente significativa para los TU desde la segunda mitad de la década de los 90 hasta el año 2009 y para los CU desde el 2010 hasta la actualidad. Ello motiva una evolución creciente en el cómputo de la suma de años completos de dedicación docente del profesorado y en la evolución del número de tesis dirigidas, tal y como se describe a continuación.

Tabla 2. Distribución por quinquenios del nombramiento de los TU y CU del área de conocimiento de ByD

\begin{tabular}{|c|c|c|c|c|c|}
\hline Período* & $\begin{array}{c}\text { No de nombramientos } \\
\text { TU* }\end{array}$ & $\begin{array}{c}\text { No de nombramientos } \\
\text { CU }\end{array}$ & $\begin{array}{l}\text { Suma de años completos de } \\
\text { dedicación docente (TU y CU) }\end{array}$ & $\mathrm{N}^{\circ}$ de tesis dirigidas & $\mathbf{R D T}^{* *}$ \\
\hline 1992-1994 & 17 & 0 & 37 & 8 & 4,6 \\
\hline 1995-1999 & 33 & 5 & 160 & 14 & 11,4 \\
\hline $2000-2004$ & 25 & 1 & 329 & 84 & 3,9 \\
\hline 2005-2009 & 32 & 0 & 418 & 90 & 4,6 \\
\hline 2010-2014 & 20 & 16 & 612 & 202 & 3,0 \\
\hline 2015-2019 & 22 & 13 & 691 & 246 & 2,8 \\
\hline Total & 152 & 35 & 2.247 & 644 & 3,4 \\
\hline
\end{tabular}

* Únicamente 3 profesores han sido nombrados como titulares de universidad antes de 1992.

** RDT: Rendimiento de la dirección de tesis.

\subsection{Evolución del número de tesis doctorales dirigidas y distribución por estatus académico, sexo y número de tesis dirigidas}

El número de tesis doctorales identificadas en las que ha participado como director o codirector algún profesor del área de conocimiento de ByD es de 644 (tabla 2). Ver listado de títulos en:

https://doi.org/10.7910/DVN/LXAFZL

Ese volumen ha generando 956 direcciones, pues en $288(44,7 \%)$ ha intervenido más de un codirector. Del total de direcciones, 715 son de PDI del área en activo y las otras 241 de docentes del área jubilados o en excedencia, de otras áreas de conocimiento o investigadores del CSIC.

La figura 1 presenta la evolución diacrónica de la producción de tesis doctorales dirigidas desagregadas en función del número de codirectores que han participado en las mismas:

- 356 tesis tienen un único director $(55,3 \%)$,

- 264 fueron codirigidas por dos codirectores (41\%), y

- 24 por tres codirectores (3,7\%).

Destaca el crecimiento de las tesis presentadas en el quinquenio 2000-2004 (con una tasa de crecimiento respecto al período anterior del $500 \%$ ) y en el quinquenio $2010-2014$ (124\%). Por otra parte, a partir de la década del 2000 se multiplican las codirecciones, superando a las tesis de director único en el período más reciente, y a partir de la década de 2010 empiezan a surgir las tesis con tres codirectores.

Únicamente un $45,2 \%$ del profesorado $(n=145)$ ha dirigido alguna tesis doctoral, entre ellos la totalidad de los actuales CU $(n=35)$, pero sola-

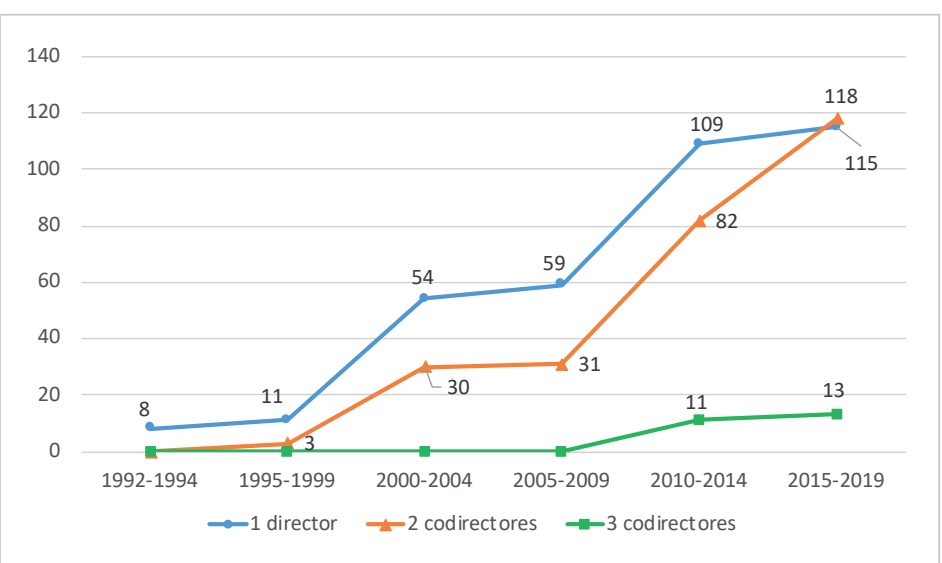

Figura 1. Evolución del número de tesis doctorales dirigidas por los docentes del área de ByD activos a comienzos del curso académico 2019-2020

mente un 76,9\% ( $n=90$ ) de los TU. El promedio de tesis dirigidas por los CU es de 10,2 \pm 8 mientras que para los TU es de $2,7 \pm 3,3$, con valores promedios de direcciones sensiblemente más reducidos en el caso de las mujeres $(1,8 \pm 4,1)$ en relación con los hombres $(2,6 \pm 4,8)$ (tabla 3 ).

Un destacado porcentaje de CD ( $n=13,46,4 \%)$ ha dirigido alguna tesis y ningún CEU y TEU ha participado en tareas de dirección de tesis, quedando relegados por detrás de las categorías de $A D(n=1,4,3 \%$ ) y "otros" ( $n=6,6,1 \%)$ que completan la distribución de las tesis dirigidas.

Otros aspectos llamativos son el hecho de que las profesoras que alcanzan la categoría de CU participan en la dirección de tesis doctorales con un peso similar $(36,8 \%)$ a la proporción que representan en la categoría (37,1\%), a diferencia de lo que ocurre en el caso de la categoría de TU, en la que los hombres superan en más de $10 \%$ a las mujeres en el número de tesis dirigidas, pese a ser mucho menor el número de hombres que ha dirigido tesis en esta categoría.

Únicamente un $45,2 \%$ del profesorado ( $n=145$ ) ha dirigido alguna tesis doctoral, entre ellos la totalidad de los actuales catedráticos de universidad $(n=35)$ 
Tabla 3. Distribución por categoría profesional y sexo del profesorado del área de ByD que ha dirigido tesis y del número de direcciones

\begin{tabular}{|c|c|c|c|c|c|c|c|c|c|c|c|c|c|c|c|}
\hline \multirow[b]{2}{*}{ Categoría } & \multicolumn{5}{|c|}{ Mujeres } & \multicolumn{5}{|c|}{ Hombres } & \multicolumn{4}{|c|}{ Total } & \multirow[b]{2}{*}{ 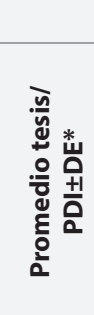 } \\
\hline & $\begin{array}{l}\overline{0} \\
\alpha \\
o \\
o \\
0 \\
z\end{array}$ & 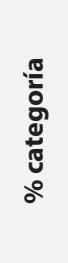 & 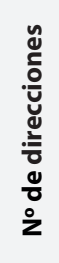 & 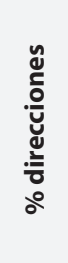 & 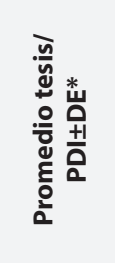 & $\begin{array}{l}\overline{0} \\
\alpha \\
o \\
o \\
0 \\
z\end{array}$ & 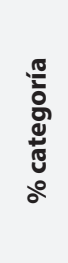 & 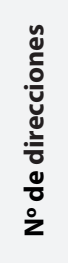 & 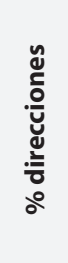 & 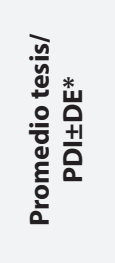 & $\begin{array}{l}\overline{0} \\
\alpha \\
\frac{0}{0} \\
\text { z } \\
\text { z }\end{array}$ & 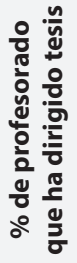 & 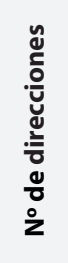 & 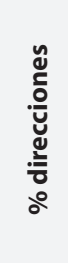 & \\
\hline $\mathrm{CU}$ & 13 & 37,1 & 131 & 36,8 & $10,1 \pm 9,8$ & 22 & 62,9 & 225 & 63,2 & $10,2 \pm 6,9$ & 35 & 100 & 356 & 49,8 & $10,2 \pm 8$ \\
\hline TU & 50 & 55,5 & 142 & 44,9 & $2,2 \pm 2,7$ & 40 & 44,4 & 174 & 55,1 & $3,3 \pm 3,8$ & 90 & 76,9 & 316 & 44,2 & $2,7 \pm 3,3$ \\
\hline CEU & 0 & 0 & 0 & 0 & 0 & 0 & 0 & 0 & 0 & 0 & 0 & 0 & 0 & 0 & 0 \\
\hline TEU & 0 & 0 & 0 & 0 & 0 & 0 & 0 & 0 & 0 & 0 & 0 & 0 & 0 & 0 & 0 \\
\hline$C D$ & 10 & 76,9 & 22 & 75,9 & $1,2 \pm 1,7$ & 3 & 23,1 & 7 & 24,1 & $0,8 \pm 1,4$ & 13 & 46,4 & 29 & 4,1 & $1 \pm 1,6$ \\
\hline$A D$ & 0 & 0 & 0 & 0 & 0 & 1 & 100 & 1 & 100 & $0,1 \pm 0,3$ & 1 & 4,3 & 1 & 0,1 & $0,0 \pm 0,2$ \\
\hline Otros & 2 & 33,3 & 4 & 30,8 & $0,1 \pm 0,4$ & 4 & 66,7 & 9 & 69,2 & $0,2 \pm 0,7$ & 6 & 6,1 & 13 & 1,8 & $0,1 \pm 0,6$ \\
\hline Total & 75 & 51,7 & 299 & 41,8 & $1,8 \pm 4,1$ & 70 & 48,3 & 416 & 58,2 & $2,6 \pm 4,8$ & 145 & 45,2 & 715 & 100 & $2,2 \pm 4,5$ \\
\hline
\end{tabular}

* Para el cálculo de los promedios se han tenido en cuenta los docentes que no han dirigido ninguna tesis

El análisis de la distribución del profesorado en función del número de tesis dirigidas (tabla 4) evidencia como aspectos más significativos el hecho de que únicamente el $8 \%$ del profesorado $(n=18)$ es responsable del $42 \%$ de las tesis dirigidas por la comunidad académica del área; así como que el 37,7\% del profesorado con funciones docentes e investigadoras (una vez excluida la categoría "otros") no ha dirigido ninguna tesis. Se constata asimismo la progresiva reducción del número de mujeres a medida que aumenta el umbral o número de tesis dirigidas, de forma que pese a que globalmente hay un número mayor de mujeres que han participado en la dirección de tesis doctorales (53,4\%), únicamente un $27,8 \%$ de las mismas $(n=5)$ han dirigido 10 o más tesis frente al $72,2 \%(n=13)$ de hombres.

Tabla 4. Distribución de los docentes del área de ByD en relación con el número de tesis dirigidas*

\begin{tabular}{|c|c|c|c|c|c|c|c|c|c|c|c|c|}
\hline \multirow{2}{*}{$\begin{array}{c}N^{\circ} \text { de } \\
\text { tesis } \\
\text { dirigidas }\end{array}$} & \multicolumn{2}{|c|}{ Mujeres } & \multicolumn{2}{|c|}{ Hombres } & \multicolumn{8}{|c|}{ Total } \\
\hline & $N^{\circ}$ de PDI & $\%$ & $N^{\circ}$ de PDI & $\%$ & $N^{\circ}$ de PDI & $\%$ & $\begin{array}{c}\mathrm{N}^{\circ} \text { de } \\
\text { direcciones }\end{array}$ & $\%$ & $\begin{array}{l}\text { No de PDI } \\
\text { (CU y TU) }\end{array}$ & $\%$ & $\begin{array}{c}\mathrm{N}^{\circ} \text { de } \\
\text { direcciones } \\
\text { (CU y TU) }\end{array}$ & $\%$ \\
\hline 0 & 46 & 54,8 & 38 & 45,2 & 84 & 37,7 & 0 & 0 & 27 & 17,8 & 0 & 0 \\
\hline 1 & 29 & 72,5 & 11 & 27,5 & 40 & 17,9 & 40 & 5,7 & 32 & 21,1 & 32 & 4,7 \\
\hline 2 & 11 & 55,0 & 9 & 45,0 & 20 & 9,0 & 40 & 5,7 & 19 & 12,5 & 38 & 5,6 \\
\hline 3 & 7 & 46,7 & 8 & 53,3 & 15 & 6,7 & 45 & 6,4 & 13 & 8,6 & 39 & 5,8 \\
\hline 4 & 5 & 38,5 & 8 & 61,5 & 13 & 5,8 & 52 & 7,4 & 11 & 7,2 & 44 & 6,5 \\
\hline 5 & 3 & 42,9 & 4 & 57,1 & 7 & 3,1 & 35 & 5,0 & 7 & 4,6 & 35 & 5,2 \\
\hline 6 & 5 & 55,6 & 4 & 44,4 & 9 & 4,0 & 54 & 7,7 & 8 & 5,3 & 48 & 7,1 \\
\hline 7 & 3 & 60,0 & 2 & 40,0 & 5 & 2,2 & 35 & 5,0 & 5 & 3,3 & 35 & 5,2 \\
\hline 8 & 4 & 57,1 & 3 & 42,9 & 7 & 3,1 & 56 & 8,0 & 7 & 4,6 & 56 & 8,3 \\
\hline 9 & 1 & 20,0 & 4 & 80,0 & 5 & 2,2 & 45 & 6,4 & 5 & 3,3 & 45 & 6,7 \\
\hline Más de 9 & 5 & 27,8 & 13 & 72,2 & 18 & 8,1 & 300 & 42,7 & 18 & 11,8 & 300 & 44,6 \\
\hline Total & 119 & 53,4 & 104 & 46,6 & 223 & 100 & 702 & 100 & 152 & 100 & 672 & 100 \\
\hline
\end{tabular}

* Se han excluido los docentes de la categoría "otros"

La figura 2 recoge la distribución de la dirección de tesis ajustada a la estimación de la productividad científica propuesta por Lotka (1926), que pone de manifiesto que el número de directores de tesis es muy superior a los valores estimados por este modelo, siendo las diferencias más acusadas entre los directores más prolíficos.

Aunque el número de mujeres (51,7\%) que dirigen tesis es superior al de los hombres (48,3\%), además de la apuntada reducción del número de mujeres a medida que aumenta el umbral del número de direcciones, se ha observado que las mujeres participan de forma mucho más reducida en las tesis dirigidas por dos o más codirectores, con únicamente un $38,5 \%(n=231)$ de codirecciones de mujeres frente al $61,5 \%(n=369)$ en el caso de los hombres. También las mujeres ocupan posiciones subordinadas, con una presencia mucho menor como primeras

A comienzos del curso académico 20192020, la comunidad académica española de ByD la formaban 321 docentes (51,1\% mujeres y $48,9 \%$ hombres) 
codirectoras (41,3\% de mujeres frente al $61,7 \%$ de hombres en las tesis con dos codirecciones; y $25 \%$ de mujeres frente al $75 \%$ de hombre en el caso de la tesis con 3 codirecciones).

La participación de las mujeres en la realización de tesis doctorales es sensiblemente superior a la de los hombres, ya que $368(59,9 \%)$ de las 644 tesis analizadas corresponden a doctorandas frente a $258(40,1 \%)$ de hombres. En relación con los vínculos director/a y doctorandos, resulta llamativa que la participación exclusivamente de mujeres (una directora que dirige a una doctoranda) presenta un valor muy reducido $(13,1 \%)$ frente al resto de los vínculos de dirección en los participan hombres (27-30\%) (tabla 5).

\subsection{Distribución del número de tesis docto- rales dirigidas por universidades y grado de optimización del rendimiento de la direc- ción de tesis (RDT)}

Globalmente, el promedio del RDT que mide la relación entre el capital humano disponible en años a tiempo completo del profesorado CU y TU y el número total de sus direcciones de tesis, se sitúa en 3,4 años (tabla 2). Así, 65 de los 125 profesores que han dirigido alguna tesis doctoral obtienen valores por encima del promedio global del área (cuanto más elevado es el RDT, peor desempeño en las funciones de dirección), a lo que cabría sumar los 27 TU que no han participado en ninguna dirección de tesis, con lo que un $60,5 \%$ de los investigadores de estas categorías ( $n=92$ ) se sitúan con un RDT que no responde al umbral promedio del área de conocimiento. Algunos casos resultan particularmente llamativos, como los 21 directores que presentan un RDT más elevado, ya que únicamente han dirigido una tesis y puntualmente dos en algún caso pese al gran número de años que han transcurrido desde su nombramiento como TU (entre 11 y 27 años).

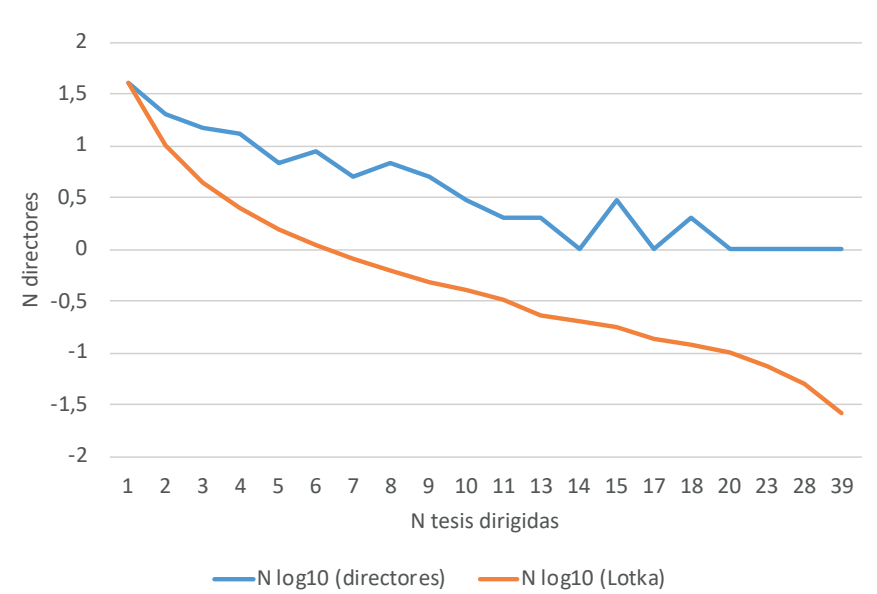

Figura 2. Relación ( $\mathrm{n} \log _{10}$ ) entre el número de directores y el modelo teórico propuesto por Lotka en relación con las tesis dirigidas por los profesores del área de ByD

Tabla 5. Distribución de la relación de directores y doctorandos por sexo

\begin{tabular}{|l|c|c|c|c|}
\hline \multirow{2}{*}{ Director/a } & \multicolumn{4}{|c|}{ Doctoranda/o } \\
\cline { 2 - 5 } & Mujer & $\%$ & Hombre & $\%$ \\
\hline Mujer & 94 & 13,1 & 205 & 28,7 \\
\hline Hombre & 218 & 30,5 & 198 & 27,7 \\
\hline
\end{tabular}

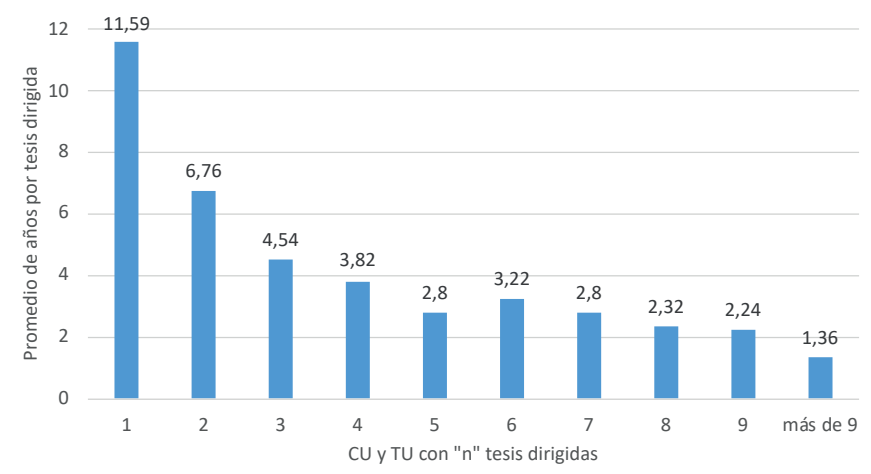

Figura 3. Relación entre la capacidad docente (años de dedicación) de los CU y TU y el número de tesis dirigidas por los profesores del área de ByD

La figura 3 mide el RDT del conjunto de CU y TU del área $(n=152)$ considerando el umbral o número de tesis dirigidas, poniendo de manifiesto que para los docentes que han dirigido una única tesis, la misma ha supuesto un promedio de dedicación (o años requeridos) en función del número de años transcurridos desde su nombramiento como TU de 11,59 años; valor que se va reduciendo progresivamente de forma que los autores más prolíficos en las funciones de dirección han dirigido de promedio una tesis cada 1,36 años. En el caso de los docentes que nunca han dirigido una tesis, el promedio de años transcurridos desde su nombramiento como funcionarios se sitúa en 11,11 años.

El análisis de la participación del personal dedicado a funciones docentes e investigadoras por universidades (tabla 6), pone de manifiesto que entre las universidades con un mayor número de PDI (27-31 PDI), la Universidad de Granada es la que presenta un mayor grado de participación de sus docentes en la dirección de tesis (70,4\%). La Universitat de Barcelona y la Universidad de Extremadura son las que presentan los valores más reducidos en relación con este indicador, destacando algunas universidades con un número puntual de docentes o sin programas de doctorado pero que presentan destacados valores de participación El $8 \%$ del profesorado $(n=18)$ es responsable del $42 \%$ de las tesis dirigidas por la comunidad académica del área de sus docentes en la dirección de tesis. 
Tabla 6. Distribución por universidades de la participación en las direcciones de tesis de los docentes del área de ByD

\begin{tabular}{|c|c|c|c|c|c|}
\hline Universidad & No de PDI* $^{*}$ & $\begin{array}{l}\% \text { de profesorado } \\
\text { que ha dirigido tesis }\end{array}$ & $N^{\circ}$ de direcciones & $\begin{array}{c}\text { No de direcciones } \\
\text { (CU y TU) }\end{array}$ & $\begin{array}{c}\text { RDT** } \\
\text { (CU y TU) }\end{array}$ \\
\hline Autònoma de Barcelona & 5 & 80,0 & 10 & 10 & 10,1 \\
\hline Alcalá de Henares & 8 & 100 & 24 & 23 & 5,1 \\
\hline Barcelona & 31 & 45,2 & 63 & 45 & 2,8 \\
\hline Carlos III de Madrid & 29 & 62,1 & 129 & 123 & 3,6 \\
\hline Complutense de Madrid & 31 & 54,8 & 79 & 71 & 2,6 \\
\hline Córdoba & 1 & 0 & 0 & 0 & 0 \\
\hline A Coruña & 2 & 50,0 & 2 & 2 & 3,5 \\
\hline Granada & 27 & 70,4 & 116 & 115 & 2,7 \\
\hline Jaume I & 1 & 100 & 6 & 6 & 1,7 \\
\hline Málaga & 2 & 100 & 2 & 2 & 17,5 \\
\hline Murcia & 12 & 58,3 & 61 & 60 & 2,5 \\
\hline Extremadura & 16 & 43,8 & 35 & 32 & 4,6 \\
\hline León & 7 & 71,4 & 6 & 6 & 9,3 \\
\hline Zaragoza & 15 & 60,0 & 38 & 38 & 6,3 \\
\hline Pompeu Fabra & 1 & 100 & 13 & 13 & 1,7 \\
\hline Politècnica de València & 7 & 100 & 30 & 29 & 1,9 \\
\hline Salamanca & 17 & 64,7 & 72 & 68 & 2,2 \\
\hline València & 11 & 72,7 & 29 & 29 & 3,5 \\
\hline Total & 223 & 62,3 & 715 & 672 & 3,4 \\
\hline
\end{tabular}

* Se excluyen los docentes de la categoría "otros" para no ofrecer una visión distorsionada y centrar el análisis en las figuras con funciones docentes e investigadoras.

** RDT: promedio entre el número de años completos de trabajo dividido por el número de tesis dirigidas.

La Universidad Complutense de Madrid y la Universidad de Granada son las universidades con un mayor número de docentes (27-31 PDI) que presentan un mayor grado de optimización de su capacidad docente en relación con la dirección de tesis medida a través del RDT, con un promedio de 2,6 y 2,7 años, respectivamente, de dedicación docente por tesis dirigida. También destaca en este indicador la Universitat de Barcelona (2,8); y más allá de las universidades con mayor número de PDI, la Universidad de Salamanca $(2,2)$ y la Universidad de Murcia $(2,5)$; y entre las universidades con un tamaño menor de plantilla, la Universitat Politécnica de Valencia (1,9). En el extremo opuesto se sitúan centros como la Universidad de León o la Universidad de Zaragoza, además de algunas universidades con un número bajo de docentes.

Finalmente, otros rasgos relevantes observados es que un destacado número de tesis de los actuales CU ( $38 \%$ de las tesis de este colectivo) fueron dirigidas cuando aún eran TU y que 45 de las tesis han sido dirigidas antes del nombramiento como TU de sus directores o por directores que son CD; y que una parte de las tesis codirigidas en las que ha participado más de un miembro de la comunidad académica analizada (48 de 71) corresponden a codirecciones de docentes de la misma universidad.

Tabla 7. Categorías temáticas de las tesis dirigidas por los docentes del área de ByD

\begin{tabular}{|c|c|c|c|c|c|c|c|c|}
\hline Área temática & $1992-94$ & 1995-99 & $2000-04$ & 2005-09 & 2010-14 & 2015-19 & Total & $\%$ \\
\hline 01 Archivos y archivística & 1 & 0 & 11 & 6 & 17 & 27 & 62 & 9,6 \\
\hline 02 Unidades y servicios de información & 4 & 1 & 10 & 30 & 41 & 36 & 122 & 18,9 \\
\hline 03 Ciencias y técnicas auxiliares & 2 & 0 & 6 & 4 & 20 & 21 & 53 & 8,2 \\
\hline 04 Estudios métricos y comunicación científica & 0 & 3 & 15 & 13 & 36 & 41 & 108 & 16,8 \\
\hline 05 Fuentes de información & 0 & 2 & 16 & 15 & 28 & 27 & 88 & 13,7 \\
\hline 06 Lenguajes y lingüística & 0 & 2 & 4 & 8 & 10 & 10 & 34 & 5,3 \\
\hline 07 Museología & 0 & 1 & 1 & 0 & 0 & 4 & 6 & 0,9 \\
\hline 08 Proceso documental & 2 & 2 & 12 & 7 & 11 & 13 & 47 & 7,3 \\
\hline 09 Profesionales & 0 & 1 & 3 & 1 & 14 & 11 & 30 & 4,7 \\
\hline 10 Usuarios & 0 & 2 & 7 & 10 & 30 & 36 & 85 & 13,2 \\
\hline 11 Sociedad de la información & 0 & 3 & 3 & 7 & 14 & 14 & 41 & 6,4 \\
\hline 12 Tecnologías de la información y comunicaciones & 0 & 0 & 15 & 16 & 27 & 27 & 85 & 13,2 \\
\hline 13 No ByD & 0 & 0 & 1 & 2 & 17 & 29 & 49 & 7,6 \\
\hline
\end{tabular}




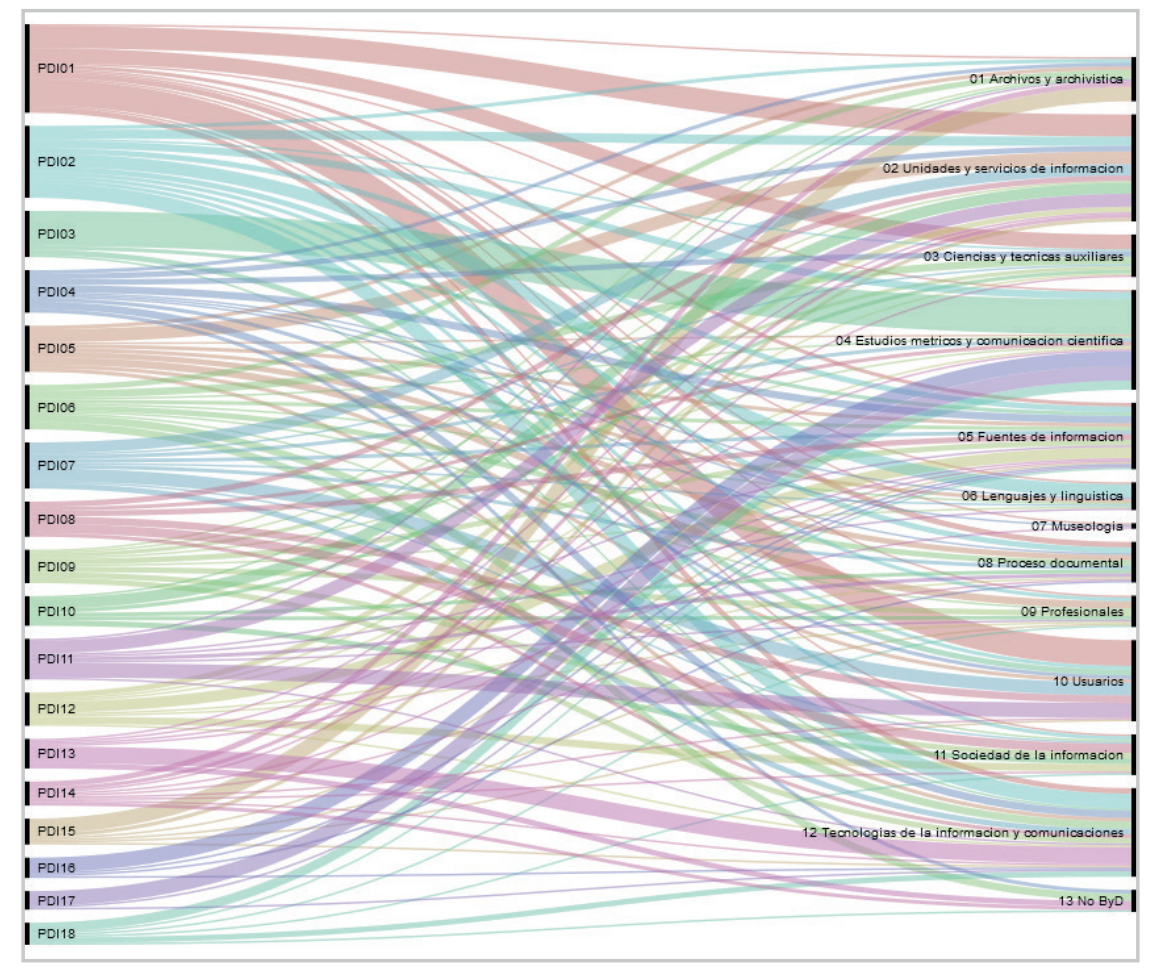

Figura 4. Áreas temáticas de las tesis dirigidas por los docentes del área de ByD con 10 direcciones o más

\subsection{Temas de las tesis doctorales y grado de especialización del PDI con más direcciones}

La tabla 7 recoge los temas de las 644 tesis doctorales analizadas dirigidas por los docentes en activo de ByD. La mayoría se han clasificado en un área temática ( $n=488$ tesis), sólo 146 se clasificaron en dos y 10 tesis en tres áreas. El porcentaje mayor corresponde a la categoría 02 Unidades y servicios de información (18,9\%), seguida por 04 Estudios métricos y publicación científica $(16,8 \%$ y y 05 Fuentes de información $(n=13,8 \%)$. No obstante, hay que señalar que en el período más reciente (2015-2019) los estudios métricos y publicación científica se sitúan como la categoría más destacada, seguidos por las tesis sobre unidades y servicios de información y sobre usuarios. También cabe resaltar que un porcentaje importante de tesis no corresponden a temas que puedan encuadrarse en la ByD.

Tabla 8. Número y áreas temáticas de las tesis dirigidas y de las publicaciones recogidas en $\mathrm{SCl}$, SSCl y Scopus de los docentes del área de ByD

\begin{tabular}{|c|c|c|c|c|c|c|c|}
\hline Director & Categoría & $\begin{array}{c}\text { Tesis } \\
\text { dirigidas }\end{array}$ & $\begin{array}{l}N^{\circ} \text { de tesis en el } \\
\text { área temática con } \\
\text { más tesis dirigidas }\end{array}$ & $\begin{array}{l}\text { ETD } \\
\text { tesis }\end{array}$ & $\begin{array}{l}\text { Artículos SCI, } \\
\text { SSCl y Scopus }\end{array}$ & $\begin{array}{l}N^{\circ} \text { de artículos en el } \\
\text { área temática con más } \\
\text { artículos publicados }\end{array}$ & $\begin{array}{c}\text { ETD } \\
\text { publicación }\end{array}$ \\
\hline PDI-01 & CU & 39 & 14 & 0,4 & 81 & 60 & 0,7 \\
\hline PDI-02 & CU & 28 & 8 & 0,3 & 30 & 10 & 0,3 \\
\hline PDI-03 & CU & 23 & 19 & 0,8 & 50 & 47 & 0,9 \\
\hline PDI-04 & CU & 20 & 4 & 0,2 & 11 & 5 & 0,5 \\
\hline PDI-05 & TU & 18 & 7 & 0,4 & 2 & 2 & 1,0 \\
\hline PDI-06 & $\mathrm{CU}$ & 18 & 4 & 0,2 & 17 & 6 & 0,4 \\
\hline PDI-07 & $\mathrm{CU}$ & 17 & 7 & 0,4 & 43 & 25 & 0,6 \\
\hline PDI-08 & $\mathrm{CU}$ & 15 & 5 & 0,3 & 20 & 8 & 0,4 \\
\hline PDI-09 & $\mathrm{CU}$ & 15 & 3 & 0,2 & 13 & 6 & 0,5 \\
\hline PDI-10 & $\mathrm{CU}$ & 15 & 6 & 0,4 & 20 & 9 & 0,5 \\
\hline PDI-11 & TU & 14 & 8 & 0,6 & 23 & 17 & 0,7 \\
\hline PDI-12 & TU & 13 & 6 & 0,5 & 8 & 4 & 0,5 \\
\hline PDI-13 & TU & 13 & 9 & 0,7 & 43 & 33 & 0,8 \\
\hline PDI-14 & $\mathrm{CU}$ & 11 & 3 & 0,3 & 17 & 11 & 0,6 \\
\hline PDI-15 & TU & 11 & 8 & 0,7 & 10 & 7 & 0,7 \\
\hline PDI-16 & CU & 10 & 8 & 0,8 & 53 & 42 & 0,8 \\
\hline PDI-17 & $\mathrm{CU}$ & 10 & 8 & 0,8 & 73 & 70 & 1,0 \\
\hline PDI-18 & $\mathrm{CU}$ & 10 & 5 & 0,5 & 35 & 19 & 0,5 \\
\hline
\end{tabular}

ETD tesis: índice de especialización temática de directores en relación con las tesis dirigidas.

ETD publicación: índice de especialización temática de directores en relación con las publicaciones en las que ha participado. 


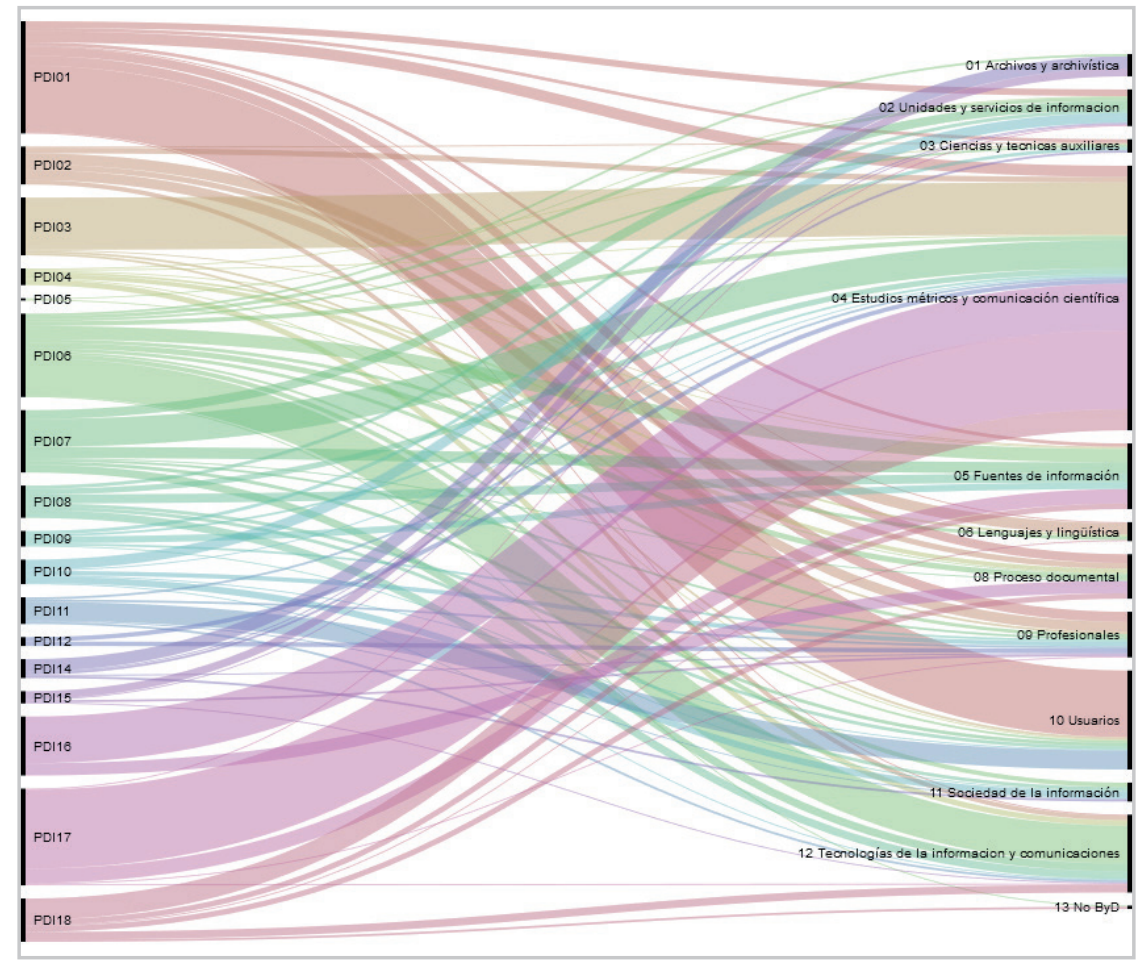

Figura 5. Áreas temáticas de los artículos de revista en los que han participado los docentes del área de ByD con 10 direcciones de tesis o más

La figura 4 presenta de forma gráfica las áreas temáticas de las tesis dirigidas por los 18 docentes con 10 o más direcciones. El primer aspecto que llama la atención es la diversidad de temas en los que se dirigen tesis. Este dato lo corrobora el índice de especialización de directores (ETD tesis), con 12 de 18 directores que presentan valores de 0,5 o inferiores (tabla 8). Así, solo un número limitado de directores presentan el valor más destacado (PDI-03, PDI-16 y PDI-17), o sea 0,8, coincidiendo además que el área de mayor dirección de tesis es la 04 Estudios métricos y comunicación científica. No obstante, aplicando un criterio más flexible, algunos de ellos presentan una especialización de una parte destacada de sus direcciones en dos temas obteniendo valores del ETD tesis entre 0,6 y 0,7 (PDI-11, PDI-13 y PDI-15). Resulta igualmente llamativo el ETD tesis de 0,2 de tres directores (PDI-04, PDI-06, PDI-09), lo que se traduce en una especialización escasa en los temas en los que dirigen tesis, y el que algunas tesis no pueden considerarse de ByD (12 tesis).

Cuando se comparan las tesis dirigidas con la lista única de artículos publicados en revistas recogidas en el $\mathrm{SCl}$, $S S C l$ y Scopus (figura 5), los temas de los artículos no son tan dispersos, sino que se concentran principalmente en la categoría 04 Estudios métricos y comunicación científica en primer lugar, seguida de las categorías 10 Usuarios y 12 Tecnologías de la información y comunicaciones. Destaca que todos los autores excepto tres han publicado al menos un artículo clasificado como 04 Estudios métricos y comunicación científica.

EI ETD publicación de los directores de tesis es mayor para el caso de la producción científica observada que para las tesis, al menos en un punto en todos los casos (tabla 8). Sólo en tres casos este índice está por debajo de 0,5 (PDI-08, PDI-06, PDI-02). Por otra parte, 5 de los 18 directores han publicado menos artículos en revistas de impacto que tesis dirigidas, con casos como el PDI-05 y el PDI-12 en los que esta diferencia es especialmente desproporcionada. Así, el escaso número de publicaciones del PDI-05 hace que tenga el máximo ETD publicación. Exceptuando esta distorsión, los docentes que tienen valores más altos en este indicador (1 y 0,9), publicaron la mayoría de sus artículos de impacto en el área 04 Estudios métricos y comunicación científica (PDI-03 y PDI-17).

\section{El 37,7\% del profesorado con funciones docentes e investigadoras no ha dirigido ninguna tesis}

\section{Discusión}

Los resultados del presente estudio ponen de manifiesto las características y los hábitos de una de las funciones más importantes del profesor universitario en el área de la ByD académica española, la dirección de tesis doctorales. Se ha observado una evolución positiva, con un destacado crecimiento en términos absolutos del número de tesis doctorales dirigidas por estos docentes en los últimos años. Es un dato que cabría esperar en una comunidad académica caracterizada por una progresiva incorporación como funcionarios de nuevos miembros desde la década de los noventa y una destacada estabilización desde 2010. Además, la consolidación de los estudios universitarios de ByD, y particularmente la implantación de programas de posgrado en la década de los 90, está sin duda en la base de la eclosión del número de tesis doctorales, aspecto ya documentado en estudios previos (Muñoz-Cañavate; Larios-Suárez, 2017; 2018; Ortiz-Repiso, 2015). Este hecho ha supuesto una mayor visibilidad de la ByD como disciplina y área de conocimiento universi- 
taria con entidad propia, reforzada además por las tesis presentadas puntualmente en departamentos de otras áreas de conocimiento con abordajes multidisciplinares o por la aplicación de enfoques propios de la ByD para el estudio de aspectos de otras disciplinas, características de buena parte de las tesis doctorales presentadas antes del año 2000 (López-López, 1996; Delgado-López-Cózar, 2000).
Las mujeres ocupan posiciones subordinadas, con una presencia mucho menor como primeras codirectoras

A pesar de esta evolución positiva, la interpretación de ese crecimiento no puede hacerse sin tener en cuenta el contexto académico en el que tiene lugar. En concreto, el de la crisis de las titulaciones de ByD y el declive del número de alumnos matriculados. Por ello, probablemente este análisis recoja aún los frutos de la implantación de los estudios de posgrado, pero es inevitable que ese declive se traslade a los estudios de doctorado y, por lo tanto, a la realización de tesis doctorales (Ortiz-Repiso; Calzada-Prado; Aportela-Rodríguez, 2013). Por otra parte, hay que tener en cuenta también el cambio de normativa de los estudios de doctorado propiciada por el Real decreto 99/2011 (España, 2011), que limitó hasta noviembre de 2015 el plazo para presentar las tesis que se iniciaron con las legislaciones anteriores, un aspecto que provocó un auténtico clamor refiriéndose la reducción de la calidad de muchas de ellas e incluso que se presentaron tesis "un poco chapuceras" (Sanmartín, 2016), que también ha podido incidir en la finalización acelerada de muchas tesis en el área de ByD inflando la cifra de direcciones, ya que es precisamente en esos dos años cuando se registra el pico más elevado de tesis presentadas.

Asimismo, algunos indicadores obligan a matizar una visión excesivamente optimista. En este sentido, además del número de PDI con funciones docentes e investigadoras que nunca ha dirigido una tesis (37,7\%) y particularmente del colectivo de TU (23,1\%), el cálculo del RDT (dirección de tesis doctorales versus capacidad de dirección de CU y TU) ha puesto de manifiesto que la gran mayoría de estos docentes con plaza funcionarial (más del 60\%) están por debajo del promedio de direcciones del área. A esto hay que añadir algunos casos particularmente llamativos en los que, a pesar de los numerosos años transcurridos desde su nombramiento como TU, no han dirigido ninguna tesis o lo han hecho de forma puntual. Esta relación desfavorable entre la antigüedad como funcionarios y la participación en la dirección de tesis doctorales debe ser considerada una debilidad del área, ya que supone una infrautilización del capital académico disponible (Eddy, 2006; Prejmerean; Vasilache, 2008). Mención aparte merecen los colectivos de CEU y TEU que no han participado en ninguna dirección de tesis, por lo que no han contribuido a través de esta faceta a la generación de nuevo conocimiento, el fomento de líneas de investigación o a la formación de las futuras generaciones de académicos e investigadores. De hecho, el presente estudio no ha identificado la tesis doctoral de muchos de los TEU analizados, por lo que ni siquiera son doctores, ya que la promoción a TU en este caso es casi automática. Aunque el mero paso del tiempo acabará con la extinción de estas categorías, cabría extraer una reflexión acerca del escaso aporte de estas figuras que contrasta con los criterios cada vez más exigentes impuestos por la Aneca para acceder a los diferentes estadios de la carrera académica.

Otro de los rasgos más significativos del estudio efectuado es la persistencia de la concentración de la dirección de tesis en un grupo limitado de directores. Aunque no presenta el grado de concentración descrito en el estudio de López-Yepes, Fernández-Bajón y Prat-Sedeño (2005b) (3 profesores dirigieron el 50\% de las tesis presentadas en el periodo 1976 2003), en el presente estudio se corrobora la elevada incidencia del fenómeno, de forma que únicamente 23 docentes (particularmente los de mayor estatus académico, 3 son catedráticas y 12 catedráticos) monopolizan más de la mitad de las tesis dirigidas. El importante desajuste observado en relación con el modelo de productividad científica propuesto por Lotka, con un número de directores prolíficos muy por encima de lo esperado, confirma que no hay una participación equilibrada en las tareas de dirección de tesis. A este respecto, no hay que olvidar que la dirección de tesis doctorales y la participación en los tribunales de evaluación, constituye uno de los ámbitos donde se ponen de manifiesto de forma más evidente las estructuras jerárquicas universitarias y los círculos sociales de poder e influencia que caracterizan el campo académico, lo que favorece el control de este proceso por parte de los docentes dotados de mayor capital social o que propicia la elección por parte de los doctorandos de los directores de mayor estatus y de mayor prestigio por su capacidad de contribuir en mayor medida al éxito futuro de la tesis y la carrera académica. (Delgado-López-Cózar et al., 2006; Moyano; Delgado-Domínguez; Buela-Casal, 1996; Fernández-Bautista; Fernández-Cano, 2015; Olmeda-Gómez et al., 2009; Merton, 1988).

Esta excesiva concentración de direcciones en una comunidad académica tan reducida, además de la infrautilización de la capacidad mentora de la mayor parte de los docentes, puede conllevar un reduccionismo de la pluralidad de enfoques de la disciplina, limitando así su potencialidad y capacidad de desarrollo, aspecto que Jiménez-Contreras, Ruiz-Pérez y Delgado-López-Cózar (2014) definen como potencial pérdida de la biodiversidad científica, al cegar la posibilidad a muchos profesores de transmitir su conocimiento; pero que también puede provocar otros fenómenos, como la endogamia, el servilismo o la mendicidad de direcciones o codirecciones para hacer frente a los requisitos meritocráticos de acreditación o promoción académica. También esta concentración puede conllevar una menor dedicación para ejercer una tutela y dirección efectiva y que no se generen los vínculos de mentorazgo que han propiciado notables avances en la investigación en muchas disciplinas, favoreciendo en cambio direcciones superficiales, incluso asumiendo la defensa de la tesis sin la rigurosidad, supervisión y crítica necesaria, asegurándose eso sí el concurso de evaluadores y tribunales afines que no vayan a plantear ninguna objeción. El hecho de que el promedio de dedicación de los directores de 10 
tesis o más sea de 1,36 años por tesis dirigida (incluso inferior entre los directores más prolíficos, en algún caso con un promedio de 7 meses por tesis dirigida) debe motivar una reflexión sobre si es una dedicación adecuada teniendo en cuenta que se debe simultanear con la dedicación a otras actividades docentes, investigadoras y una cada vez más sobrecargada agenda de actividades de gestión e incluso de difusión o transferencia.

También el fenómeno de la concentración de las tesis doctorales se pone de manifiesto a nivel de universidades, de forma que únicamente tres centros monopolizan casi la mitad de las tesis dirigidas (Universidad Carlos III, Universidad de Granada y Universidad Complutense de Madrid), manteniéndose e incluso incrementándose la concentración mostrada en estudios previos (López-Yepes; Fernández-Bajón; Prat-Sedeño, 2005b; Oliva-Marañón, 2014). Aunque no se han producido variaciones significativas en relación con los principales centros de referencia, el presente estudio ha permitido determinar la existencia de diferencias entre los centros donde se ha dirigido un mayor número de tesis más allá de limitarse a cuantificar el número de tesis dirigidas, con algunas universidades que además de integrar en mayor medida a su plantilla en las tareas de dirección (medido a través del \% de profesorado que ha dirigido tesis), presentan una mejor optimización de su capacidad de dirección de tesis (medida a través del RDT), caso de la Universidad Granada y la Universidad de Salamanca, que obtienen valores muy positivos en ambos indicadores, a las que se suma en el caso del segundo de ellos (el RDT) la Universitat de Barcelona y la Universidad Complutense de Madrid.

La nula o baja participación de muchos de los docentes universitarios en la dirección de tesis observada en el presente estudio se puede poner en relación con la escasa participación de una buena parte de la comunidad académica del área en las publicaciones científicas (González-Alcaide; Gorraiz, 2018), pese a que ambas facetas deberían constituir una parte esencial de sus actividades junto a la práctica docente. En relación con las tesis doctorales, cabría plantearse en qué medida la no participación en las tareas de dirección responde a un efecto sistémico atribuible a la concentración del capital social en unos pocos académicos; o en qué medida es fruto del desinterés, desidia o incapacidad para dirigir; o si es posible que incidan otros factores, como la debilidad del área de conocimiento

La excesiva concentración de direcciones puede provocar endogamia, servilismo o mendicidad para hacer frente a los requisitos meritocráticos de acreditación o promoción académica

con la ausencia de programas de doctorado en algunas universidades o de candidatos potenciales. La identificación y abordaje de estos factores sería esencial para tratar de favorecer la consolidación del área, puesto que constituye, como se ha indicado, un aspecto de gran relevancia, ya que más allá de que no se cumpla a nivel individual con uno de los cometidos del profesor universitario, supone un debilitamiento del desarrollo intelectual de una disciplina científica.

Más allá del fenómeno de la concentración de las tesis dirigidas entre los CU y que este colectivo presente un promedio de direcciones muy superior al de los TU, los resultados del presente estudio ponen de manifiesto que la dirección de tesis doctorales se ha erigido en un mérito de gran relevancia en relación con los procesos de promoción académica, como lo prueba el hecho de que una parte importante de las direcciones de los actuales CU (38\%) fueron presentadas cuando aún eran TU y que muchos TU de nombramiento reciente se han iniciado en la dirección de tesis antes de acceder a esta categoría (32 tesis analizadas en el presente estudio han sido leídas antes del nombramiento de sus directores como TU, además de otras 13 tesis de docentes que aún son CD). También la consideración de la dirección de tesis doctorales como destacado mérito curricular en los procesos de acreditación puede relacionarse con el fenómeno de la eclosión de la codirección de tesis de la última década, pudiendo ser otra manifestación del llamado efecto Aneca (González-Alcaide, 2019; Soriano-Clemente, 2008), al igual que ha ocurrido con el crecimiento las autorías injustificadas sobre el que han alertado diferentes estudios (Gómez-Ferri; González-Alcaide; Llopis-Goig, 2019; Smith et al., 2019). En este punto cabría plantearse cuestiones como el valor que aporta la codirección, si está justificada (López-Yepes; Ros-García, 2003) y en qué medida se está cumpliendo lo que marca la legislación, que refiere que solo es admisible en razón de la interdisciplinariedad temática o cuando se trate de programas desarrollados en colaboración nacional o internacional.

Algunos de los resultados del presente estudio, particularmente el hecho de que 48 de las 71 codirecciones en las que ha participado más de un miembro de la comunidad académica analizada sean de la misma institución y departamento parecen estar reflejando un carácter endogámico que no justificaría en muchos casos la necesidad de la codirección, pudiendo responder más a motivos extracadémicos como pueden ser impulsar los currículos de colaboradores afines o de integración de investigadores noveles en un contexto marcado, tal y como se ha señalado, por la concentración de la función de dirección en un grupo reducido de académicos. De esta manera, la dirección (o en su defecto la codirección) de tesis estaría convirtiéndose en un mérito más que necesario a nivel curricular, con lo que tal vez podría adaptarse y ampliarse el inquietante mantra o aforismo de "publica o muere" a "publica y dirige o muere". Otro incentivo más para la apresurada, resultadista y generalmente mala ciencia.

Otro resultado de gran relevancia constatado en este trabajo son los desequilibrios entre hombres y mujeres en el ámbito académico, ampliamente documentados en la bibliografía científica (Villarroya et al., 2008). Pese a que globalmente existe paridad en la población de docentes
La dirección de tesis doctorales se ha erigido en un mérito de gran relevancia en relación con los procesos de promoción académica 
analizada y que el número de mujeres que han dirigido alguna tesis es ligeramente superior al de los hombres, los resultados confirman lamentablemente la persistencia de los desequilibrios que se pueden medir de forma muy precisa a través de indicadores bibliométricos. Así, entre los resultados más llamativos está el menor grado de participación en la dirección de tesis, una progresiva reducción del peso de las mujeres a medida que aumenta el umbral del número de tesis dirigidas y una menor presencia de mujeres en las tesis codirigidas y subordinada frecuentemente a la participación de un hombre como primer codirector. Más allá de la reiteración de un fenómeno extensamente documentado, cabría reivindicar la necesidad de adoptar medidas que permitan corregir estos desequilibrios y que en muchos casos tienen su efecto más inmediato en la mayor dificultad de promoción de las mujeres frente a los hombres.

Por último, la determinación de las áreas temáticas de las tesis, su estudio pormenorizado en el caso de los docentes que han dirigido 10 tesis o más y la vinculación de estas áreas con sus publicaciones científicas, ha revelado resultados sobre prácticas actuales que pueden predecir algunos rasgos futuros del área nada halagüeños. Así, el hecho de que no haya una especialización temática de las tesis dirigidas entre buena parte de los directores más productivos debe considerarse una importante limitación o rasgo negativo que opera también en contra de la institucionalización cognitiva de la disciplina. Entendemos que un director de tesis debería volcar su conocimiento especializado (que difícilmente será tal dada la heterogeneidad de temáticas que aborda en muchos casos) en el proceso de dirección, dejando su "impronta" sobre las tesis que dirige. Esta dispersión puede responder nuevamente al hecho de que se esté primando, por parte de los directores, más el hecho de dirigir que la coherencia y los resultados del proceso de dirección (López-Yepes; Ros-García, 2013); o bien reflejar que es en muchos casos el doctorando el que propone el tema y selecciona al director guiado por criterios de prestigio o influencia más que por sus líneas de investigación, tratándose en cualquier caso de circunstancias anómalas que no responden a la lógica investigadora (García-de-León, 2010). Por el contrario, los mayores niveles de especialización de dan en direcciones de tesis clasificadas dentro de la categoría de estudios métricos y publicación científica. Esto, junto con el hecho de que esta área y diferentes docentes e investigadores vinculados a la misma se hayan erigido en referentes internacionales (Kawalec, 2013; Olmeda-Gómez; De-Moya-Anegón, 2016; Pandita; Singh, 2015; Walters; Wilder, 2016) nos lleva a pensar que esta línea puede erigirse, si no lo es ya, en el único o principal futuro del área a nivel investigador, quedando en el olvido otras líneas de investigación que tradicionalmente han constituido la base de la disciplina, como la biblioteconomía, los lenguajes documentales o la recuperación de información.

Respecto a la relación entre las tesis dirigidas por los directores más prolíficos y la publicación en revistas científicas recogidas en $\mathrm{SCl}, \mathrm{SSCl}$ y Scopus, resulta especialmente llamativo que algunos de ellos o no han participado o apenas han realizado alguna contribución puntual, con algunos casos de directores que han dirigido numerosas tesis (incluso en un solo año) pero que o no tienen o apenas tienen visibilidad internacional a través de artículos de revista, lo que constituye una manifestación palmaria de que cantidad no es igual a calidad. Podría alegarse que existe una preferencia por otros canales de comunicación, como los libros o las comunicaciones a congresos, pero no hay que olvidar que la publicación en revistas científicas, que exige una revisión externa más rigurosa y nada cooptativa, es sinónimo de difusión y de transferencia de conocimiento, y ésta a su vez el vehículo a través del cual una disciplina científica se consolida y evoluciona. En este sentido, no solo es problemático que el director (y por lo tanto mentor de futuros investigadores) no tenga los hábitos de publicación deseables en un investigador activo, sino también que las tesis que ha dirigido no hayan derivado en una publicación científica en medios de amplia difusión, ya que cada vez existe mayor consenso acerca del hecho de que la publicación de los resultados de la tesis refuerza su valor y el currículo de todo aquel que se inicia en la carrera académica, al someter la capacidad investigadora y sus resultados al escrutinio de la comunidad científica (Sánchez-Jiménez et al., 2017), redundado además positivamente en la institucionalización cognitiva de una disciplina. Cabe plantearse a qué responde este fenómeno y qué implicaciones puede tener para la investigación de la disciplina, pudiendo ser un indicador que refleje una baja calidad de algunas tesis o que se esté primando la obtención del grado de doctor o los beneficios que lleva aparejados para el director, por encima de la generación de nuevo conocimiento y su difusión (Jiménez-Contreras; Ruiz-Pérez; Delgado-López-Cózar, 2014).

\section{Limitaciones y líneas de futuro}

El presente estudio ha tenido como objetivo analizar la dirección de tesis de una comunidad académica concreta, el área de conocimiento de la ByD en las universidades públicas españolas. Con ello, se ha actualizado la visión descriptiva de los estudios previos, en un momento particularmente crítico en el que su enseñanza en las universidades está tomando rumbos desconocidos hasta la fecha. Poniendo el foco en esta comunidad en concreto, se han dejado de lado las tesis vinculadas a la disciplina en las que no han participado docentes del área en activo (por ejemplo, por excedencias o jubilaciones); así como las tesis en las que han participado profesionales o investigadores del campo, pero vinculados al CSIC u otros organismos; y las tesis con contenidos propios de la disciplina dirigidas por académicos de otras áreas de conocimiento o en univer- 
sidades privadas. Esta decisión era necesaria para obtener una visión que primara los medios de la investigación por encima de sus productos y partiendo, como se ha apuntado en la introducción, de que no hay ciencia sin estructura social que la sustente. Por lo tanto, la visión ofrecida debe complementarse con un análisis más exhaustivo, identificando las escuelas académicas y las genealogías derivadas de los procesos de dirección y analizando la estructura y el capital acumulado de los docentes, investigadores o profesionales del área derivado de su participación y de las interacciones que han establecido como miembros de los tribunales de exposición y defensa de las tesis doctorales.

\section{Conclusión}

A pesar del importante crecimiento del número de tesis dirigidas por los docentes del área de conocimiento de ByD, se han constatado importantes desequilibrios, entre los que destacan la persistencia de una elevada concentración de las direcciones de tesis y la falta de una clara especialización temática de muchos de los directores más prolíficos. Estos y otros desequilibrios descritos en el presente estudio en relación con un aspecto de relevancia capital para una disciplina científica, como es la formación de las futuras generaciones de docentes e investigadores y el impulso de las líneas de investigación a través de la dirección de tesis doctorales, se erigen como una amenaza más que se debe tener presente por parte de los académicos e investigadores de la disciplina.

\section{Referencias}

Abadal, Ernest (1994). La documentación en España. Madrid: CSIC. ISBN: 8400074319

Agustín-Lacruz, María-del-Carmen; Salvador-Oliván, José-Antonio; Velasco-de-la-Peña, Esperanza (2009). "La invisibilidad de las tesis doctorales de información y documentación en la Universidad de Zaragoza”. En: Lloret-Romero, Núria (coord.). Nuevas perspectivas para la difusión y organización del conocimiento: actas del IX Congreso ISKO España, pp. 461-469. https://dialnet.unirioja.es/servlet/articulo?codigo $=2923347$

Crane, Diana (1972). Invisible colleges: diffusion of knowledge in scientific communities. Chicago: University of Chicago. ISBN: 0226118576

De-Moya-Anegón, Félix; Jiménez-Contreras, Evaristo; De-la-Moneda-Corrochano, Mercedes (1998). “Research fronts in library and information science in Spain (1985-1994)". Scientometrics, v. 42, n. 2, pp. 229-246.

https://doi.org/10.1007/BF02458357

Delgado-López-Cózar, Emilio (2000). “Diagnóstico de la investigación en biblioteconomia y documentación en España (1976-1996): estado embrionario". Revista de investigación iberoamericana en ciencia de la información y documentación, v. 1, n. 1, pp. 79-93.

http://eprints.rclis.org/13833

Delgado-López-Cózar, Emilio (2002). La investigación en Biblioteconomía y Documentación. Gijón: Trea. ISBN: 8497040414 http://eprints.rclis.org/13935

Delgado-López-Cózar, Emilio; Torres-Salinas, Daniel; Jiménez-Contreras, Evaristo; Ruiz-Pérez, Rafael (2006). “Análisis bibliométrico y de redes sociales aplicado a las tesis bibliométricas defendidas en España (1976-2002): temas, escuelas científicas y redes académicas". Revista española de documentación científica, v. 29, n. 4, pp. 493-524.

https://doi.org/10.3989/redc.2006.v29.i4.306

Eddy, Mattew D. (2006). "Academic capital, postgraduate research and British universities: a Bourdieu inspired reflection". Discourse: learning and teaching in philosophical and religious studies, v. 6, n. 1, pp. 211-223.

http://dro.dur.ac.uk/17486

España (2011). "Real decreto 99/2011, de 28 de enero, por el que se regulan las enseñanzas oficiales de doctorado". $B O E$, n. 35, 10 febrero.

https://www.boe.es/buscar/act.php?id=BOE-A-2011-2541

Fernández-Bautista, Andrés; Fernández-Cano, Antonio (2015). “La ley de la ventaja acumulada en la distribución de tesis doctorales españolas de educación y sus directores". En: Investigar con y para la sociedad, v. 2. Cádiz: Bubok, pp. 1179-1187. http://aidipe2015.aidipe.org

Ferran-Ferrer, Núria; Guallar, Javier; Abadal, Ernest; Server, Adan (2017). "Research methods and techniques in Spanish library and information science journals (2012-2014)". Information research, v. 22, n. 1, paper 741. http://InformationR.net/ir/22-1/paper741.html

Finlay, Craig S.; Sugimoto, Cassidy R.; Li, Daifeng; Russell, Terrell G. (2012). "LIS dissertation titles and abstracts (19302009): Where have all the librar* gone?". The library quarterly, v. 82, n. 1, pp. 29-46.

https://doi.org/10.1086/662945

Fuentes-Pujol, Maria-Eulàlia; González-Quesada, Alfons (2002). "Tesis doctorales en España en información y documentación (1976-2001)”. En: Morán-Suárez, María A.; Rodríguez-López, María-del-Carmen. La documentación para la investigación. Homenaje a José Antonio Martín Fuertes. León: Universidad de León, pp. 231-241. ISBN: 8477198837 
Fuentes-Pujol, Maria-Eulàlia; González-Quesada, Alfons (2001). “La investigación y la literatura especializada en información y documentación: una revisión". Scire, v. 7, n. 2, pp. 11-38.

https://www.ibersid.eu/ojs/index.php/scire/article/view/1148

García-de-León, María-Antonia (2000). "Sobre las tesis doctorales (el caso de las Ciencias Sociales)". Sociedad y utopía: revista de ciencias sociales, v. 15, pp. 51-80.

https://dialnet.unirioja.es/servlet/articulo?codigo $=178358$

Gómez-Ferri, Javier; González-Alcaide, Gregorio; Llopis-Goig, Ramón (2019). “Measuring dissatisfaction with coauthorship: an empirical approach based on the researchers' perception". Journal of informetrics, v. 13, n. 4, 100980. https://doi.org/10.1016/j.joi.2019.100980

González-Alcaide, Gregorio (2019). “El efecto Aneca en la producción científica de los investigadores españoles: querían evaluar y acabaron efectuando meros conteos". En: Campos de investigación de vanguardia. Madrid: Ediciones Pirámide. ISBN: 9788436842715

González-Alcaide, Gregorio; Gorraiz, Juan (2018). "Assessment of researchers through bibliometric indicators: The area of information and library science in Spain as a case study (2001-2015)". Frontiers in research metrics and analytics, v. 18 , n. 3. https://doi.org/10.3389/frma.2018.00015

Guallar, Javier; Ferran-Ferrer, Núria; Abadal, Ernest; Server, Adan (2017). "Revistas científicas españolas de información y documentación: análisis temático y metodológico". El profesional de la información, v. 26, n. 5, pp. 947-960.

https://doi.org/10.3145/epi.2017.sep.16

Jiménez-Contreras, Evaristo; Ruiz-Pérez, Rafael; Delgado-López-Cózar, Emilio (2014). “El análisis de las tesis doctorales como indicador evaluativo: reflexiones y propuestas". Revista de investigación educativa, v. 32, n. 2, pp. $295-308$.

https://doi.org/10.6018/rie.32.2.197401

Kawalec, Anna (2013). "Research trends in library and information science based on Spanish scientific publication 2000 to 2010". Malaysian journal of library and information science, v. 18, n. 2, pp. 1-13.

https://mjlis.um.edu.my/article/view/1864

López-López, Pedro (1996). “La investigación bibliométrica en España (tesis doctorales)”. Revista española de documentación científica, v. 19, n. 1, pp. 84-89.

http://redc.revistas.csic.es/index.php/redc/article/view/634/709

López-Yepes, José (2002a). “Focos de investigación y escuelas científicas en documentación. La experiencia de las tesis doctorales". El profesional de la información, v. 11, n. 1, pp. 46-52.

http://www.elprofesionaldelainformacion.com/contenidos/2002/enero/6.pdf

López-Yepes, José (2002b). “Focos de investigación y escuelas científicas en documentación a través de la realización y dirección de tesis doctorales. El caso del Departamento de Biblioteconomía y Documentación de la Universidad Complutense de Madrid (1983-2001)". Documentación de las ciencias de la información, v. 25, pp. 19-54.

https://revistas.ucm.es/index.php/DCIN/article/view/DCIN0202110019A

López-Yepes, José; Fernández-Bajón, María-Teresa; Prat-Sedeño, Judit (2005a). "La investigación española en documentación informativa a examen en Ibersid 2004. Estado de la cuestión con especial referencia a las tesis doctorales (1976-2004)". El profesional de la información, v. 14, n. 1, pp. 50-57.

http://www.elprofesionaldelainformacion.com/contenidos/2005/enero/8.pdf

López-Yepes, José; Fernández-Bajón, María-Teresa; Prat-Sedeño, Judit (2005b). “Las tesis doctorales en Biblioteconomía y Documentación. Diagnóstico y propuesta de criterios de evaluación". Documentación de las ciencias de la información, v. 28, pp. 173-187.

https://revistas.ucm.es/index.php/DCIN/article/view/DCIN0505110173A

López-Yepes, José; Ros-García, Juan (2003). “Problemas relativos a la evaluación investigadora de los profesores universitarios del área de Biblioteconomía y Documentación”. Revista general de información y documentación, v. 13, n. 2, pp. 37-58. https://revistas.ucm.es/index.php/RGID/article/view/RGID0303220037A

Lotka, Alfred J. (1926). "The frequency distribution of scientific productivity". Journal of the Washington Academy of Sciences, v. 16, n. 12, pp. 317-323.

Mauri, Michele; Elli, Tommaso; Caviglia, Giorgio; Uboldi, Giorgio; Azzi, Matteo (2017). "RAWGraphs: A visualisation platform to create open outputs". In: Proceedings of the $12^{\text {th }}$ Biannual conference on Italian SIGCHI Chapter, art. 28.

https://doi.org/10.1145/3125571.3125585

Maz-Machado, Alexander; Bracho-López, Rafael; Torralbo-Rodríguez, Manuel; Gutiérrez-Arenas, María-Pilar; Jiménez-Fanjul, Noelia; Adamuz-Povedano, Natividad (2012). "Redes académicas generadas por las tesis doctorales de educación matemática en España”. Revista de investigación educativa, v. 30, n. 2, pp. 271-286.

https://doi.org/10.6018/rie.30.2.116421 
Merton, Robert K. (1988). "The Matthew effect in Science, II. Cumulative advantage and the symbolism of intellectual property". ISIS, v. 79, n. 4, pp. 606-623.

http://doi.org/10.1086/354848

Mochón-Bezares, Gonzalo; Sorli-Rojo, Ángela (2002). Tesauro de Biblioteconomía y Documentación. Madrid: CSIC. ISBN: 8400080912

http://hdl.handle.net/10261/30255

Moyano, Manuel; Delgado-Domínguez, Carlos J.; Buela-Casal, Gualberto (1996). “Análisis de la productividad científica de la Psiquiatría española a través de las tesis doctorales en la base de datos Teseo (1993-2002)". International journal of psychology and psychological therapy, v. 6, n. 1, pp. 111-120.

https://dialnet.unirioja.es/servlet/articulo?codigo=2190989

Muñoz-Cañavate, Antonio; Larios-Suárez, Verónica (2017). “Postgraduate studies in librarianship and information science in Spain". Education for information, v. 33, n. 3, pp. 153-169.

https://doi.org/10.3233/EFI-160087

Muñoz-Cañavate, Antonio; Larios-Suárez, Verónica (2018). "Los estudios de grado en Información y Documentación en España. De los antecedentes a la situación actual: una visión crítica”. Transinformação, v. 30, n. 3, pp. 336-347.

https://doi.org/10.1590/2318-08892018000300006

Oliva-Marañón, Carlos (2014). "Visibilidad y líneas de investigación de las tesis doctorales en biblioteconomía y documentación en las universidades españolas (2001-2012)". Prisma social, v. 12, pp. 615-645.

http://www.isdfundacion.org/publicaciones/revista/numeros/12/secciones/abierta/a-02-tesis-biblioteconomia.html

Olmeda-Gómez, Carlos; De-Moya-Anegón, Félix (2016). "Publishing trends in library and information sciences across European countries and institutions". Journal of academic librarianship, v. 42, n. 1, pp. 27-37.

https://doi.org/10.1016/j.acalib.2015.10.005

Olmeda-Gómez, Carlos; Perianes-Rodríguez, Antonio; Ovalle-Perandones, María-Antonia; De-Moya-Anegón, Félix (2009). "Colegios visibles: estructuras de coparticipación en tribunales de tesis doctorales de Biblioteconomía y Documentación en España”. El profesional de la información, v. 18, n. 1, pp. 41-49.

http://doi.org/10.3145/epi.2009.ene.06

Orera-Orera, Luisa (2004). "Las tesis sobre biblioteconomía y bibliotecas y su accesibilidad a través de las bibliotecas universitarias españolas”. En: López Yepes, José; López-López, Pedro; Fernández-Bajón, María-Teresa (coords.). Estudios de biblioteconomía y documentación: homenaje a la profesora María Rosa Garrido Arilla. Madrid: Escuela Universitaria de Biblioteconomía y Documentación, Universidad Complutense de Madrid, pp. 91-102. ISBN: 8460924866

Ortiz-Repiso, Virginia (2015). "Rethinking library and information studies in Spain: crossing the boundaries". BiD: textos universitaris de biblioteconomia i documentació, v. 35.

https://doi.org/10.1344/BiD2015.35.12

Ortiz-Repiso, Virginia; Calzada-Prado, Javier; Aportela-Rodríguez, Ivett M. (2013). “¿Qué está pasando con los estudios universitarios de biblioteconomía y documentación en España?”. El profesional de la informacion, v. 22, n. 6, pp. 505-514. http://doi.org/10.3145/epi.2013.nov.02

Ortiz-Sánchez, Sarivette; Martín-Moreno, Carmen (2011). “Las tesis doctorales como instrumento para conocer la evolución de la producción en biblioteconomía y documentación: el caso del departamento de Biblioteconomía y Documentación de la Universidad Carlos III". Investigación bibliotecológica, v. 25, n. 55, pp. 151-174.

https://doi.org/10.22201/iibi.0187358xp.2011.55.32860

Pandita, Ramesh; Singh, Shivendra (2015). "Research growth in LIS during last decade: a study". Library review, v. 64, n. 8-9, pp. 514-532.

https://doi.org/10.1108/LR-04-2015-0037

Prejmerean, Mihaela C.; Vasilache, Simona (2008). "A three-way analysis of the academic capital of a Romanian university". Journal of applied quantitative methods, v. 3, n. 2, pp. 129-138.

http://www.jaqm.ro/issues/volume-3,issue-2/2_prejmerean_vasilache.php

Repiso, Rafael; Torres-Salinas, Daniel; Delgado-López-Cózar, Emilio (2011). “Análisis bibliométrico y de redes sociales en tesis doctorales españolas sobre televisión (1976/2007)". Comunicar, v. 18, n. 37, pp. 151-159.

https://doi.org/10.3916/C37-2011-03-07

Sánchez-Jiménez, Rodrigo; Blázquez-Ochando, Manuel; Montesi, Michela; Botezan, Iuliana (2017). “La producción de tesis doctorales en España (1995-2014): evolución, disciplinas, principales actores y comparación con la producción científica en WoS y Scopus". Revista española de documentación científica, v. 40, n. 4, pp. e188.

https://doi.org/10.3989/redc.2017.4.1409 
Sanmartín, Olga R. (2016). “El 'boom' de las tesis doctorales: 12.100 lecturas en sólo seis meses. El mundo, 3 marzo. https://www.elmundo.es/sociedad/2016/03/08/56dc6d7546163ffd4c8b45aa.html

Smith, Elise; Williams-Jones, Bryn; Master, Zubin; Larivière, Vincent; Sugimoto, Cassidy R.; Paul-Hus, Adèle; Shi, Min; Resnik, David B. (2019). "Misconduct and misbehavior related to authorship disagreements in collaborative science". Science and engineering ethics, v. 26, pp. 1967-1993.

https://doi.org/10.1007/s11948-019-00112-4

Soriano-Clemente, Jaume (2008). "El efecto Aneca". En: I+C Investigar la comunicación. Congreso internacional fundacional AE-IC. Santiago de Compostela, 30-31 enero, 1 febrero. ISBN: 9788461238163

Sugimoto, Cassidy R. (2016). Toward a twenty-first century dissertation. Council of Graduate of Schools. http://cgsnet.org/ckfinder/userfiles/files/1_1\%20Sugimoto.pdf

Villarroya, Anna; Barrios, Maite; Borrego, Ángel; Frías, Amparo (2008). “PhD theses in Spain: a gender study covering the years 1990-2004". Scientometrics, v. 77, n. 3, pp. 469-483.

https://doi.org/10.1007/s11192-007-1965-8

Walters, William H.; Wilder, Esther I. (2016). "Disciplinary, national, and departmental contributions to the literature of library and information science, 2007-2012". Journal of the American Society for Information Science and Technology, v. 67, n. 6, pp. 1487-1506.

http://doi.org/10.1002/asi.23448

Whitley, Richard (1984). The intellectual and social organization of the sciences. Oxford: Clarendon Press. ISBN: 9780 198272489

Zapico-Alonso, Felipe; Reyes-Barragán, María-Josefa; Guerrero-Bote, Vicente P.; López-Pujalte, Cristina (2002). “La investigación en documentación: análisis bibliométrico de las tesis en documentación". En: Morán-Suárez, María A.; Rodríguez-López, María-del-Carmen. La documentación para la investigación: Homenaje a José Antonio Martín Fuertes. León: Universidad de León, pp. 689-713. ISBN: 8477198837

\section{Anexo}

Equivalencia entre los árboles jerárquicos del tesauro de referencia y la clasificación empleada en el presente estudio, así como los descriptores que se asignaron no presentes en el tesauro.

\begin{tabular}{|c|c|c|}
\hline Árboles jerárquicos tesauro CSIC & Categorías temáticas de las tesis & Descriptores asignados no presentes en el tesauro \\
\hline $\begin{array}{l}\text { Archivística } \\
\text { Unidades de información-Archivos }\end{array}$ & 01 Archivística y archivos & $\begin{array}{l}\text { Administración electrónica, Documento electrónico de } \\
\text { archivo, Historia de la archivística }\end{array}$ \\
\hline $\begin{array}{l}\text { Biblioteconomía } \\
\text { Unidades de información - Bibliotecas y } \\
\text { centros de documentación }\end{array}$ & 02 Unidades y servicios de información & Planificación de sistemas de información \\
\hline Ciencias y técnicas auxiliares & 03 Ciencias y técnicas auxiliares & Historia de la fotografía, Historia del papel \\
\hline Estudios métricos de la información & $\begin{array}{l}04 \text { Estudios métricos y comunicación } \\
\text { científica }\end{array}$ & $\begin{array}{l}\text { Altmétricas, Divulgación científica, Open acces, Ran- } \\
\text { kings universitarios, Repositorios en el contexto del OA }\end{array}$ \\
\hline Fuentes de información & 05 Fuentes de información & E-books, Repositorios como fuente de información \\
\hline Lenguajes y lingüística & 06 Lenguajes y lingüística & - \\
\hline $\begin{array}{l}\text { Museología } \\
\text { Unidades de información-Museos }\end{array}$ & 07 Museología & - \\
\hline Proceso documental & 08 Proceso documental & Gestión de datos de investigación \\
\hline \multirow[b]{2}{*}{$\begin{array}{l}\text { Profesionales de la información y } \\
\text { usuarios }\end{array}$} & 09 Profesionales & - \\
\hline & 10 Usuarios & $\begin{array}{l}\text { Alfabetización informacional, Competencias digitales, } \\
\text { Competencias informacionales, Comportamiento in- } \\
\text { formacional, Comunidades de práctica, Uso de fuentes } \\
\text { de información }\end{array}$ \\
\hline Sociedad de la información & 11 Sociedad de la información & - \\
\hline $\begin{array}{l}\text { Tecnologías de la información y comu- } \\
\text { nicaciones }\end{array}$ & $\begin{array}{l}12 \text { Tecnologías de la información y comu- } \\
\text { nicaciones }\end{array}$ & $\begin{array}{l}\text { Aplicaciones móviles, Sindicación de contenidos, Sis- } \\
\text { temas de gestión de contenidos-CMS, Visualización de } \\
\text { información, Web social, Posicionamiento web }\end{array}$ \\
\hline- & 13 No biblioteconomía y documentación & - \\
\hline
\end{tabular}

